\title{
Yellow adipocytes comprise a new adipocyte sub-type present in human bone marrow
}

Camille Attanél\#, David Estève ${ }^{1 \#}$, Karima Chaoui ${ }^{1}$, Jason Iacovoni ${ }^{2}$, Jill Corre ${ }^{3}$, Mohamed Moutahir ${ }^{1}$, Philippe Valet $^{4}$, Odile Schiltz ${ }^{1}$, Nicolas Reina ${ }^{5,6}$, Catherine Muller $^{1}$

${ }^{1}$ Institut de Pharmacologie et de Biologie Structurale (IPBS), Université de Toulouse, CNRS, UPS, Toulouse, France

${ }^{2}$ Plateau de Bioinformatiques, Institut des Maladies Métaboliques et Cardiovasculaires (I2MC), Université de Toulouse, INSERM, UPS, Toulouse France

${ }^{3}$ Centre de Recherches en Cancérologie de Toulouse (CRCT), Université de Toulouse, INSERM, UPS, Toulouse, France

${ }^{4}$ Institut des Maladies Métaboliques et Cardiovasculaires (I2MC), Université de Toulouse, INSERM, UPS, Toulouse, France

${ }^{5}$ Département de Chirurgie Orthopédique et Traumatologique, Hôpital Pierre-Paul Riquet, CHU de Toulouse, Toulouse, France

${ }^{6}$ Laboratoire AMIS, UMR 5288 CNRS, Université Toulouse III-Paul Sabatier, Toulouse, France

\# Contributed equally to this work

Corresponding author(s): Pr Catherine Muller, IPBS CNRS UMR 5089, 205 route de Narbonne, 31077 Toulouse Tel: 33-561-17-59-32; Fax: 33-561-17-59-33; e-mail: muller@ipbs.fr

\section{Running title}

Defect of lipolysis in bone marrow adipocytes

\section{Abstract}

During energy demanding conditions, white adipocytes store triglycerides and release fatty acids through lipolysis. In contrast, bone marrow adipocytes (BM-Ad) increase in size during caloric restriction, suggesting this fat depot exhibits precise metabolic specificity. We found subcutaneous adipocytes (SC-Ad) and BM-Ad share morphological features, but possess distinct lipid metabolism. BM-Ad show enrichment in cholesterol-oriented metabolism that correlates with increased free cholesterol content, while proteins involved in lipolysis were downregulated. A strong down-regulation in expression of monoacylglycerol (MG) lipase was observed leading to an accumulation of major MG species and accordingly the basal and induced lipolytic responses were absent in BM-Ad. These features are not recapitulated in vitro using differentiated bone marrow mesenchymal stem cells. Since our data demonstrate that BM-Ad comprise a distinct class of adipocytes, we propose renaming them yellow adipocytes.

\section{Keywords}

Bone Marrow adipocytes / cholesterol/lipolysis / monoacylglycerol lipase / proteomic 


\section{Introduction}

In mammals, white adipose tissue (WAT) accumulates at various sites throughout the body. The most important and well-studied fat deposits occur in subcutaneous regions (SC-AT) and in the abdominal cavity surrounding key internal organs like the pancreas and intestines (Zwick et al, 2018). Other adipose-specific deposits also form around the heart, kidney, prostate in men and mammary glands in women (Zwick et al, 2018). In addition to WAT, mammals also possess brown adipose tissue (BAT) located in the interscapular and supraclavicular regions, representing less than 5\% of the total fat mass (Leitner et al, 2017; Nedergaard et al, 2007; Saito et al, 2009; Zingaretti et al, 2009). Brown adipocytes participate in non-shivering thermogenesis and possess a specific morphology that includes several small lipid droplets and high mitochondria content (Bartelt \& Heeren, 2014; Cinti, 2001). In contrast, white adipocytes store energy as triglycerides (TG) in their unique large lipid droplet (LD) after energy intake and release free fatty acids (FFA) through lipolysis in energy demanding conditions (Zechner, 2015). Lipolysis occurs through a biochemical pathway that uses consecutive actions of adipose triglyceride lipase (ATGL), which catalyzes the conversion of TG to diacylglycerols (DG) and hormone-sensitive lipase (HSL) and hydrolyzes DAG to monoacylglycerols (MG), monoacylglycerol lipase (MAGL) and the newly identified $\alpha / \beta$ hydrolase domain-containing protein 6 (ABHD6), which hydrolyzes MG to FA (Zhao et al, 2016) and glycerol (Zechner, 2015). White adipocytes also have an important endocrine function as they can release multiple soluble factors called adipokines, such as leptin and adiponectin (Fasshauer \& Blüher, 2015).

One intriguing adipose tissue (AT) localizes to the bone marrow called bone marrow adipose tissue (BM-AT) that constitutes over $10 \%$ of the total fat mass in lean and healthy humans (Cawthorn et al, 2014). Technological advances in quantitative imaging of BM-AT in both mice and humans revealed that BM-AT presents unique features that highlight their physiological specificity. Many studies demonstrated that BM-AT increases in different pathophysiological conditions such as aging (Justesen et al, 2001; Scheller et al, 2015), osteoporosis (Justesen et al, 2001; Yeung et al, 2005) and obesity (Bredella et al, 2010; Doucette et al, 2015). These findings suggest this adipocyte population plays a larger role beyond that of "filler-cells". In stark contrast to the other WAT, the number and size of bone marrow adipocytes (BM-Ad) also increase during caloric restriction conditions in mice (Cawthorn et al, 2014; Devlin et al, 2010), rabbits (Bathija et al, 1979; Tavassoli, 1974) and human patients suffering from anorexia nervosa (Abella et al, 2002; Bredella et al, 2010). Decreases in bone marrow adiposity occurs only in severe nutrient deprivation in rabbits (Cawthorn et al, 2016) and late stages of anorexia nervosa associated with gelatinous transformation of the bone marrow (BM) [(Abella et al, 2002); for review (Ghali et al, 2016)].

Given the significant role for AT in regulating energy homeostasis, it is critical to elucidate why this tissue copes with changes in energy status in such a specific way that leads to still store and not dispense fuel when needed. However, knowledge of the phenotype of primary BM-Ad in physiology is sparse and hampered by difficulty to obtain sufficient isolated BM-Ad in mice and from harvesting human BM-AT partly due to the physical location (inside bone). Most studies on BM-Ad use rodents or human in vitro models. Mouse studies indicate BM-Ad regulate hematopoiesis and bone mass (Naveiras et al, 2009; Zhou et al, 2017). However, species-specific differences between rodent and human BM-AT exist that reinforce using caution when extrapolating information across species (Scheller et al, 2016). Two types of adipocytes in mouse have been described: regulatory and constitutive BM-Ad (rBM-Ad and cBM-Ad, respectively) (Scheller et al, 2015). cBM-Ad are present in tail vertebrae and the medullary canal from the tibia-fibular junction into the malleolus. However, rBM-Ad develop 
1 postnatally within the BM of long bones extending from below the growth plate through the metaphysis and into 2 the diaphysis (Scheller \& Rosen, 2014). Existence of these two populations remains unconfirmed in humans. Inside 3 the diaphysis of long bone, the number of BM-Ad varies between mouse strains and species, and some strains 4 require pharmacological induction of BM-Ad by drugs such as glucocorticoids and thiazolidinedione (Scheller et 5 al, 2016). Yet, human BM-Ad consistently fill 50 to $70 \%$ of the bone marrow cavity (Hindorf et al, 2010). Many 6 studies use bone marrow mesenchymal stromal cells (BM-MSC) differentiated in adipocytes in vitro. However, it 7 is unclear whether these differentiated cells recapitulate the phenotype of mature human primary BM-Ad. These 8 in vitro studies suggest a role for BM-Ad in hematopoiesis regulation (Mattiucci et al, 2018; Naveiras et al, 2009), 9 bone remodeling (Hardaway et al, 2015) and cancer progression (Diedrich et al, 2016; Herroon et al, 2013; Liu et al, 2015; Shafat et al, 2017; Tabe et al, 2017). These issues highlight that our knowledge of the physiological phenotype of primary BM-Ad remains limited. Using combined lipidomic and proteomic large-scale approaches, we purified and characterized human BM-Ad harvested from the femoral diaphysis of patients undergoing hip surgery with paired subcutaneous adipocytes (SC-Ad) and found that BM-Ad exhibit clearly distinct lipid metabolic features that reveal a new adipocyte sub-type. 


\section{Results/Discussion}

\section{Isolated SC-Ad and BM-Ad share morphological properties of white adipocytes.}

After harvesting paired SC-AT and BM-AT from patients undergoing hip replacement surgery, we isolated adipocytes after collagenase digestion (Fig 1A). In AT from both locations, the vast majority of the space contained large and cohesive mature adipocytes with a unique LD filled with neutral lipids (assessed by Bodipy staining) (Fig 1B). Mature adipocytes from both locations expressed perilipin 1 (PLIN1) at the surface of the LD (Fig EV1 AB) and exhibited a very thin cytoplasm rim, a morphological trait expressed by white adipocyte (Fig EV1B) (Cinti, 2001). SC-AT and BM-AT also contained blood vessels highly positive for actin staining and stroma vascular cells at both stromal and perivascular positions (Fig 1B and Fig EV1A). Using transmission electron microscopy approach, we observed that both SC-Ad and BM-Ad present in the AT display a large LD surrounded by a very thin cytoplasm with the nucleus located at the cell periphery between the plasma membrane and the LD (Fig 1C). We performed an enzymatically based digestion protocol to isolate adipocytes from both tissues. After obtaining a population of cells constituted only of adipocytes, our results indicated that our tissue dissociation preserved the morphological identity of the isolated adipocytes. The isolated BM-Ad and SC-Ad shared the same morphology found within the tissues characterized by the presence of a unique and large LD filled with neutral lipids (Fig 1D). In addition, F-Actin staining showed a similar cytoskeleton architecture between the two types of cells (Fig 1D). Taken together, our results demonstrate the BM-AT present in the diaphysis of long bone is composed of cohesive adipocytes that exhibit the morphological appearance of white adipocytes as assessed by their unique LD, surrounded by a thin cytoplasm and a nucleus present at the periphery of the cells. With the caution noted in the introduction, a recent study in mice that used electronic transmission found that BM-Ad exhibit similar rounded morphology with a unique large LD (Robles et al, 2019). Yet, a recent report suggested that mouse BM-Ad express some genes related to BAT, including PRDM16 and FOXC2 (Krings et al, 2012). However, this study used whole tibia extracts, which contain adipocytes and contaminating cells, including myeloid cells and osteoblasts that express PRDM16 and FOXC2, respectively (Kim et al, 2009; Nishikata et al, 2011). Here, we present an initial morphological characterization of human BM-Ad, where they exhibit traits of white adipocytes that do not clearly distinguish them from "classical" white adipocytes.

\section{Lipid profile in BM-Ad reveals enriched diverse lipid species like monoacylglycerol (MG) and cholesterol.} We then further characterized the phenotype of BM-Ad by studying their lipid profile compared to SC-Ad. Lipids were extracted from tissues and isolated adipocytes. As shown in Fig 2A, each tissue and isolated adipocytes showed a similar total lipid content. A quantitative LC-MS/MS based analysis of the total lipid content extracted from BM-Ad and SC-Ad was performed using a recently developed approach that uses both positive and negative ionization modes to cover the largest spectrum of detectable lipid species (Breitkopf et al, 2017). The analysis structurally characterized and identified 818 lipid species originating from the main lipid categories that belonging to 15 lipid classes. The majority of identified lipid species were glycerolipids (GL), including triacylglycerol (TG, $95 \%$ ) and diacylglycerol (DG, 2.1\%). Beyond GL, the remaining lipids contain a large spectrum of phospholipids (PL), in particular phosphatidylcholine (PC, 1.9\%), a major membrane constituent (Wen et al, 2018), sphingolipids (SL) and fatty esters (Fig 2B).

Unsupervised multivariate analyses of our lipidomic dataset indicated the variance between samples predominantly arose through inter-individual variability (Fig EV2A-B) indicating the lipids stored within mature 
adipocytes likely came from food intake. We conclude that BM-Ad lipid composition reflects dietary lipid intake, which is consistent with a prior report in SC-Ad (Hodson et al, 2008). We then investigated if differences exist in lipid classes between SC-Ad and BM-Ad by comparing all quantified lipid species for one class between the two locations. As shown in Fig 2C, we observed differences in GL content. BM-Ad, in all samples, exhibited a slight increase in TG content with no changes in DG levels. MG content increased (Fig 2C), which reflected an increase of both saturated and unsaturated major MG species (Fig EV2C). These results suggest that the hydrolysis of MG is not efficient in BM-Ad. Two additional lipid classes are also increased in BM-Ad compared to SC-Ad, wax esters and sphingosine. Of note, only three sphingosine species were detected. The LC-MS/MS approach we used to quantify the lipid species does not identify cholesterol species, a key lipid species contained in adipocyte LD (Schreibman \& Dell, 1975). Using a colorimetric assay, we found that BM-Ad showed a 1.5 -fold increase in free cholesterol content compared to SC-Ad (Fig 2D). Cholesterol ester was not detected in either sample as we predicted since the vast majority of cholesterol is expressed in a free form in adipocytes (Schreibman \& Dell, 1975). Here, we characterize the lipid content in BM-Ad using unsupervised lipidomic approaches. Interindividual variability suggests that BM-Ad lipid content partially reflects dietary intake as in other adipose depots. Our results demonstrate that intrinsic differences exist between BM-Ad and SC-Ad regarding free cholesterol and MG contents.

\section{Proteome of BM-Ad and SC-Ad differentiates adipocytes in lipid metabolic functions}

We sought to further decipher the metabolic pathways specifically present in BM-Ad, so we conducted a largescale proteomic analysis on paired SC-Ad and BM-Ad. We detail the data analysis general strategy in Fig EV3A. After data quality control, 3259 proteins were robustly detected. Interestingly, when we searched for proteins known to be secreted by adipocytes, termed adipokines (Fasshauer \& Blüher, 2015), our dataset did not highlight significant differences between the two types of adipocytes and K-means clustering based on the expression pattern of adipokines did not allow clustering of the samples according to their anatomical location (Fig EV3B). BM-Ad expressed the adipocyte-specific adipokine, adiponectin, at the same levels as SC-Ad (Fasshauer \& Blüher, 2015) (ADIPOQ, Table EV1). We obtained similar results for leptin (LEP, Table EV1), a hormone predominantly produced by adipocytes (Fasshauer \& Blüher, 2015). These results indirectly assess the quality of cell preparation and their purity.

Among the 3259 proteins detected, 612 proteins involved in glucose and lipid metabolism were identified. We performed an unsupervised multivariate analysis focused on these proteins, which clearly demarcated the 4 samples according to their anatomical location (Fig 3A). The first two components of this analysis explained $41 \%$ and $20.8 \%$ of the dataset variance, respectively (Fig 3A). Statistical analysis of the 612 metabolic proteins differentially expressed in BM-Ad compared to SC-Ad identified 68 up-regulated proteins and 67 down-regulated proteins (Fig 3B). Pathway enrichment analysis with gene analytic software showed clear differences in the expression of proteins involved in several lipid metabolism pathways according to their anatomical locations (Fig 3C). Compared to SC-Ad, BM-Ad showed enrichment in arachidonic acid (AA) metabolism, SL signaling pathway and cholesterol metabolism delineated through cholesterol biosynthesis and statin pathways, while BMAd displayed downregulation of glucose and FA metabolism, as well as lipolysis regulation pathways (Fig 3C). Lipoprotein metabolism was also enriched and down-regulated in BM-Ad compared to SC-Ad (Fig 3C). In depth analysis of the proteins differentially expressed in this pathway revealed unexpected specificity for each fat depot. 
We uncovered a clear separation of the samples by their location using hierarchical clustering dendrogram (Fig 3D). In BM-Ad, proteins involved in cholesterol transport (apoliproproteins APO-A2, -C1 and -C4) and hydrolysis, such NCEH1 (Neutral Cholesterol Ester Hydrolysis) and LIPA (Lipase A) (Litvinov et al, 2018), were enriched. This cholesterol-oriented metabolism in BM-Ad is strengthening by the enrichment of several proteins involved in cholesterol biosynthesis and statin pathways (Fig EV3C). On the opposite, proteins related to lipolysis were down-regulated in BM-Ad compared to SC-Ad in lipoprotein metabolism pathway (Fig 3D). Surprisingly, the lipases involved in TG hydrolysis LIPE (gene name of HSL) and MGLL (gene name of MAGL) were decreased ( $1.19 \pm 0.80, p=0.016$ for LIPE and $-2.45 \pm 0.35 p=0.00024$ for MGLL, see Table EV1), as well as the Fatty Acid Binding Protein 4 (FABP4), one of the most abundant proteins in adipocytes that participate in maintaining adipocyte homeostasis and regulating lipolysis and adipogenesis (Prentice et al, 2019). Finally, BM-Ad and SCAd exhibited distinct expression patterns of proteins involved AA metabolism and FA metabolism (Fig EV3D-E). Despite similar morphology and expression pattern of adipokines, our results strongly support that BM-Ad are adipocytes that exhibit a very specific lipid metabolism compared to the "classical" SC-Ad. We uncovered an accumulation of free cholesterol in these cells. This conclusion is supported by unbiased proteomic approaches that indicate a seemingly unidentified cholesterol-oriented metabolism. In contrast to our results, a recent transcriptomic study comparing gene expression of human BM-Ad isolated from the femoral head and SC-Ad show that genes over-represented in human BM-Ad participate in signaling pathways without clear differences in the enzymes involved in lipid metabolism (such as cholesterol metabolism and TG hydrolysis) (Mattiucci et al, 2018). In addition, this report found decreased adiponectin expression, which stand in contrast to our current results and another study that identified BM-Ad as an important source of adiponectin (Cawthorn et al, 2014). We speculate technical issues, such as transcriptomic vs proteomic, and the different sources of BM-AT used may underlie the differences in these findings. We suspect that the specificity of BM-Ad in cholesterol metabolism may reflect their role in supporting BM hematopoiesis (Naveiras et al, 2009; Zhou et al, 2017). Cholesterol is essential constituent of the plasma membrane (Abe \& Kobayashi, 2017) and could sustain cell division and plasma membrane fluidity and synthesis of surrounding hematopoietic cells that are under constant renewal. In contrast, the main functions of adipocytes, liberating energy reserve stores as TG under times of energy demand, appears downregulated in these cells. This interesting observation is consistent with the absence of a decrease in BM adiposity under energy deficit conditions (Bathija et al, 1979; Cawthorn et al, 2014; Devlin et al, 2010; Tavassoli, 1974). In particular, we observed a critical down-regulation of MAGL expression, a lipase required for the final hydrolysis of MG produced by HSL activation (Zechner, 2015). As such, MAGL deficiency in mice leads to a concomitant increase in MG levels in AT (Taschler et al, 2011) as observed in BM-Ad. The concomitant decrease of MAGL expression and increase in MG species strongly suggests that MAGL activity may be impaired in BMAd compared to SC-Ad.

\section{Human primary BM-Ad present a defect in lipolytic activity not recapitulated in in vitro models}

Due to the potential high impact of this newly described regulation in BM-Ad physiology, we further characterized the lipolytic pathway using Western blot analysis of the three major lipases involved in the consecutive hydrolysis of TG. While we observed no differences in ATGL and HSL expression in BM-Ad compared to paired SC-Ad, we found a sharp decrease (about 5-fold) in MAGL (Fig 4A). While we found a slight (1.21-fold) decrease in HSL protein expression in our proteomic studies, this result was not reproduced using Western blot analysis. This 
discrepancy highlights inter-individual variability. We then functionally assayed lipolytic activity using ex vivo approaches on isolated adipocytes. Under basal conditions, we observed reduced glycerol and FFA release in BMAd compared to SC-Ad (Fig 4B and 4C). Under isoprenaline stimulation (a $\beta$-adrenergic agonist that serves as a strong lipolytic inductor) (Lafontan \& Langin, 2009), we found no increase in glycerol (reflecting complete lipolytic reactions) or significant FFA release, but we did find a 3-fold increase in SC-Ad as expected (Lafontan \& Langin, 2009). Thus, our data clearly demonstrate that human BM-Ad are devoid of lipolytic activity, which confirms their metabolic specificity.

A key finding from our study is the profound down-regulation of MAGL expression, which has never been reported for other AT. Strikingly, the two lipases ATGL and HSL possess several regulators of their activity involving interaction with other proteins as well as phosphorylation state under the control of hormones such as catecholamines (Lafontan \& Langin, 2009). However, there is no evidence that cell energy status or hormones can influence MAGL activity, which renders it constitutively active (Lafontan \& Langin, 2009). Since BM-Ad downregulate MAGL expression, this indicates that these cells use the only efficient way to inhibit this specific activity. The slight, but not significant, increase of FFA upon lipolytic stimulation in BM-Ad (Fig 4C) suggests that the lipolysis process is not completely effective in these cells. In mice, a study suggests that rat cBM-Ad (from tail vertebrae) and rBM-Ad (from proximal tibia and femur) are resistant to lipolysis induced by $\beta$-adrenergic stimuli. This corresponds at the molecular level to a decrease in active phosphorylation of HSL, whereas the levels of ATGL and HSL remained unchanged compared to SC-Ad (Scheller et al, 2019). Such an additional regulatory process could also occur in human BM-Ad. Interestingly, the MAGL defect in BM-Ad is not compensated by ABHD6 expression, another lipase known to hydrolyze MG in visceral and brown AT but not in SC-AT (Zhao et al, 2016). ABHD6 expression levels remained constant between BM-Ad and SC-Ad in our proteomic study (Table EV1).

We then focused on the metabolic characteristic of BM-Ad we discovered, so we examined the physiological relevance of in vitro differentiated adipocytes used as the gold standard model for studying the role of BM-Ad. We differentiated human primary BM-MSCs and murine BM-MSC OP9 cell lines in vitro under adipogenic conditions. The murine pre-adipocyte 3T3-F442A served as a control reflecting "classical adipocytes". In all cells, the differentiation process strongly increased TG content (Fig 4D). In vitro differentiated adipocytes from BMMSCs exhibited similar levels of basal lipolysis compared to differentiated 3T3-F442A (Fig 4E). Isoprenaline stimulation increased glycerol release in all cells studied (Fig 4E). These experiments demonstrated that adipocytes obtained from in vitro differentiation of human BM-MSCs do not recapitulate the functional defect in lipolysis observed in BM-Ad isolated from patients. We conclude from these results that in vitro differentiated BM-MSCs, considered the gold standard for studying BM-Ad functions, should be interpreted with high caution, since these cells do not recapitulate of key metabolic trait of the BM-Ad phenotype. The differentiation program of BM-Ad may exhibit distinct developmental gene expression patterns and epigenetic signatures that are not induced by the most widely used differentiation protocols that add PPAR $\gamma$ agonists (Lee \& Fried, 2014; Ninomiya et al, 2010; Scott et al, 2011). We suggest that such protocols may artificially force BM-Ad progenitors towards a differentiation program into classical white adipocytes. 


\section{Conclusion}

2 Here, we pioneered a methodology to characterize human primary BM-Ad using combined large-scale proteomic 3 and lipodomic approaches. This approach revealed specific markers in a phenotype that refines and identifies BM-

4 Ad. These cells morphologically resemble classical SC-Ad; however, we unraveled the specific lipid metabolism 5 of BM-Ad, including the presence of a cholesterol-orientated metabolism that requires further investigation. We 6 demonstrated altered lipolytic function in human primary BM-Ad due to a profound down-regulation of MAGL 7 expression. This result underlies the differences in metabolic fitness upon caloric restriction between BM-AT and 8 SC-AT. This specific phenotype is a previously unidentified feature of adipose depots that could explain why BM9 AT behaves like a preserved lipid source, except during periods of extremely severe nutrient deprivation (Abella 10 et al, 2002; Cawthorn et al, 2016). The specific function of this preservation, whether overall metabolic fitness or local interaction with proximal cells (such as hematopoietic cells), remains unknown. Adipocyte diversity continues to increase, so distinguishing markers and delineating specific phenotypes of these adipocyte subtypes gain importance. In addition to white and brown adipocytes, recent studies have identified beige adipocytes, an inducible form of thermogenic adipocytes (Zwick et al, 2018) and pink adipocytes in mouse mammary fat pad during pregnancy and lactation (Giordano et al, 2014). Given their specificity for lipid metabolism regardless of their morphological similarity to white adipocytes, we propose to define BM-Ad as a distinct type of adipocytes named "yellow adipocytes". 


\section{$1 \quad$ Materials and Methods}

\section{Human subcutaneous and bone marrow tissue samples.}

Paired subcutaneous (SC-AT) and bone marrow adipose tissue (BM-AT) were harvested from patients undergoing hip surgery in the Orthopedic Surgery and Traumatology Department of the Hospital Pierre Paul Riquet (Toulouse, France). All patients gave their informed consent and the samples were obtained according to national ethic committee rules (authorization $^{\circ}$ DC-215-2342). Briefly, during total hip replacement surgeries, after skin incision, maximus gluteus muscle and external rotators dissection, an osteotomy of the femoral neck was performed which allowed access to the intramedullary canal. While broaching the canal, BM-AT was aspirated cautiously with a soft cannula in the femoral proximal metaphysis and diaphysis before prosthesis placement. All procedures were performed using the same posterior approach. SC-AT were harvested using surgical blade at the incision site in the gluteal region. The samples were immediately placed in $37^{\circ} \mathrm{C}$ pre-warmed KRBHA (Krebs Ringer BSA HEPES Albumin buffer) corresponding to Krebs Ringer buffer (Sigma-Aldrich) supplemented with 100mM Hepes (Sigma-Aldrich) and $0.5 \%$ free fatty acid (FFA-free) bovine serum albumin (BSA) (Sigma-Aldrich) and rapidly carried out to the laboratory (within 1h) where they were processed. The BM-AT that share the same macroscopic aspects compared to SC-AT was dissected from area rich in hematopoietic cells (red marrow). For all the experiments performed in our study, 24 independent samples were used and obtained from 14 men and 10 women (mean age: $66.7 \pm 13.9$ years and mean body mass index (BMI): $26.8 \pm 3.4 \mathrm{~kg} / \mathrm{m}^{2}$ ).

\section{Adipocyte isolation.}

SC-AT and BM-AT were rinsed several times in KRBHA prior to collagenase digestion (250 UI / $\mathrm{mL}$ diluted in PBS calcium and magnesium free supplemented with 2\% FFA-free BSA (all products were obtained SigmaAldrich). After 30 min digestion at $37^{\circ} \mathrm{C}$ under constant shaking, samples were filtered with 100 and $200 \mu \mathrm{m}$ cell strainers (for BM-AT and SC-AT respectively) to remove cellular debris, undigested fragments and bone trabeculaes. The cell suspension was then gently centrifuged for $5 \mathrm{~min}$ at $200 \mathrm{~g}$ at room temperature (RT). The floating adipocytes were then collected and rinsed with KRBHA several times to obtain a pure adipocyte cell suspension.

\section{SC-AT and BM-AT confocal microscopy}

Pieces of $0.5 \mathrm{~cm}^{2}$ of whole SC-AT and BM-AT were fixed with a 4\% paraformaldehyde solution (PFA, Electron Microscopy Sciences (EMS)) overnight. Fixed tissues were blocked and permeabilized in calcium and magnesium free PBS supplemented with 3\% BSA and 0.2\% Triton X100 (both obtained from Sigma Aldrich) for $1 \mathrm{~h}$ at RT. Tissues were then incubated overnight with a mouse anti PLIN1 serum (Acris Biosystem; 1:10 in calcium and magnesium free-PBS, 3\% BSA, $0.2 \%$ Triton X-100). The following day the tissues were rinsed 5 times in PBS 0.05\% Tween-20 and incubated for $2 \mathrm{~h}$ with a secondary antiboby coupled with CF488 dye (Biotum) for PLN1 staining, rhodamine coupled phalloidin (Thermofisher) for filamentous actin staining and TOPRO3 ${ }^{\circledR}$ (Thermofisher) for nuclei staining. Z-stack images were acquired using LSM 710 confocal microscope and a 10X or 40X objective (Zeiss). Maximum intensity projection was made using Image $\mathrm{J}$ software and orthogonal views using Imaris software (v9.2; Bitplane). 


\section{Transmission electron microscopy}

SC-AT and BM-AT were fixed with 2,5\% glutaraldehyde and 2\% PFA (EMS, Hatfield, PA, USA) in Cacodylate buffer $(0.1 \mathrm{M}, \mathrm{pH} 7.2)$ overnight at $4{ }^{\circ} \mathrm{C}$ and post-fixed at $4{ }^{\circ} \mathrm{C}$ with $1 \% \mathrm{OsO} 4$ and $1.5 \% \mathrm{~K} 3 \mathrm{Fe}(\mathrm{CN}) 6$ in the same buffer. Samples were treated for $1 \mathrm{~h}$ with $1 \%$ aqueous uranyl acetate and were then dehydrated in a graded ethanol series and embedded in EMBed-812 resin (EMS). After $48 \mathrm{~h}$ of polymerization at $60^{\circ} \mathrm{C}$, ultrathin sections $(80 \mathrm{~nm}$ thick) were mounted on 75 mesh formvar-carbon coated copper grids. Sections were stained with $2 \%$ uranyl acetate (EMS) and 3\% Reynolds lead citrate (Chromalys). Grids were examined with a TEM (Jeol JEM-1400, JEOL Inc) at $80 \mathrm{kV}$. Images were acquired using a digital camera (Gatan Orius, Gatan Inc, Pleasanton, CA, USA).

\section{Confocal microscopy on isolated adipocytes}

BM-Ad and SC-Ad were isolated as described above. Immediately after isolation, primary adipocytes were embedded in a fibrin gel to maintain cellular integrity. Briefly, $30 \mu 1$ of isolated adipocytes were gently mixed with $30 \mu \mathrm{l}$ of a fibrinogen solution ( $18 \mu \mathrm{g} / \mathrm{mL}$ in $0.9 \% \mathrm{NaCl}$ buffer, Sigma-Aldrich) and $30 \mu 1$ of thrombin (3 units in $30 \mu 1$ of $\mathrm{CaCl}_{2}$ solution, Sigma-Aldrich). Gel polymerization occurs rapidly at $37^{\circ} \mathrm{C}$. The gels containing the primary adipocytes were fixed in $4 \%$ PFA for $1 \mathrm{~h}$ and incubated with $10 \mathrm{ng} / \mathrm{mL}$ of Bodipy ${ }^{\circledR} 493 / 503$, rhodamine coupled phalloidin and TOPRO3 (all products were obtained from Thermofischer). Samples were examined using LSM 710 confocal microscope and a 40X objective (Zeiss). Maximum intensity projection was performed using Image J software.

\section{Lipidomic analysis}

For the lipidomic and proteomic studies, 4 samples were used ( 2 men and 2 women, mean age: $67 \pm 7.4$ years; mean BMI: $\left.26.5 \pm 3.1 \mathrm{~kg} / \mathrm{m}^{2}\right)$. After 3 washes with PBS, isolated adipocytes $(400 \mu \mathrm{l})$ were mixed $1.5 \mathrm{~mL}$ methanol in glass tubes. Sample mixture was then incubated with $5 \mathrm{~mL}$ of methyl tert-butyl ether (MTBE ;Sigma-Aldrich) for $1 \mathrm{~h}$ at RT under gently shaking. After adding $1.2 \mathrm{~mL}$ of water, samples were centrifuged for $10 \mathrm{~min}$ at $1000 \mathrm{~g}$. Upper phase (containing lipids) was transferred in a new glass tube. Lower phase was re-extracted with 2 volume parts of MTBE: methanol: water (10: 3: 2.5) and samples were centrifuged for $10 \mathrm{~min}$ at $1000 \mathrm{~g}$ and used for proteomic analyses (see below). Upper phase was collected, combined with the one collected after the first extraction and kept at $-80^{\circ} \mathrm{C}$ for lipidomic analysis. One $\mathrm{ml}$ of lipid phase was evaporated under a nitrogen stream. Dried samples were sent to the Harvard mass spectrometry core and were analyzed by their untargeted lipidomics profiling platform. Lipids were resuspended with $100 \mu \mathrm{l}$ of 1:1 LC/MS grade isopropanol: acetonitrile methanol and $5 \mu 1$ were injected onto the LC-MS/MS. Data acquisition was performed as previously described (Breitkopf et al, 2017). Briefly, each peaks area was calculated in both positive and negative ionization mode. The peaks allowing to structurally resolving the same lipid species were sum, if obtained from the same ionization. Only the lipid species detected at least in 3 samples from the same location were considered as robustly detected and used for the analysis. Missing values were imputed as the first percentile of the entire dataset. Then, values were $\log 2$ transformed and normalized with the function NormalizeBetweenArrays from Bioconductor package to perform the principal component analysis with R software (v3.5) and FactomineR package. The heatmaps and associated hierarchical clustering build on K-means methods were resolved with R software and ggplot2 package after centering the data around zero. The lipid species belonging to the same classes were sum to measure their relative 
abundance and the $\log 2$ fold change of signal intensities for each class was calculated to compare the lipid classes between adipocyte locations. Violin plot was drawn with vioplot function in R.

\section{Cholesterol content quantification}

Cholesterol content within isolated adipocytes was measured using cholesterol assay kit (obtained from Abcamab65390) according to manufacturer recommendations. Briefly, lipids were extracted from isolated adipocytes using MTBE as described above. Free cholesterol and total cholesterol was sequentially quantified using colorimetric method. Optical density was determined at $570 \mathrm{~nm}$ with $\mu$-quant spectrophotometer (BioTek Instruments).

\section{Proteomic analysis}

After 3 washes with PBS, proteins from isolated adipocytes $(400 \mu \mathrm{l})$ were purified with $5 \mathrm{~mL}$ of MTBE as described in lipidomic analysis section. Lower phase was centrifuged for $10 \mathrm{~min}$ at $5000 \mathrm{~g}$ at RT and pellet (containing proteins) was washed 2 times with PBS to remove solvents. Pellets were then resuspended with PBS 2\% SDS,

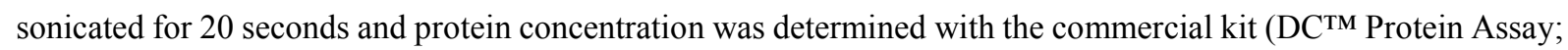
Bio-Rad). Fifteen $\mu \mathrm{g}$ of proteins were reduced with modified Laemmli buffer (40 mM Tris pH 6.8, 2\% SDS, 10\% glycerol, $25 \mathrm{mM}$ DTT and $0.01 \%$ bromophenol blue) for $15 \mathrm{~min}$ at $65^{\circ} \mathrm{C}$ and alkylated by addition of $90 \mathrm{mM}$ iodoacetamide for $30 \mathrm{~min}$ at RT in the dark. Protein samples were loaded on a 1D SDS-PAGE gel $(0.15 \times 8 \mathrm{~cm})$ and the electrophoretic migration was stopped as soon as the proteins entered the separating gel, in order to isolate all proteins in a single gel band (stained with Coomasie blue). The corresponding gel slice was excised and washed with $100 \mathrm{mM}$ ammonium bicarbonate buffer. Proteins were in-gel digested using $0.6 \mu \mathrm{g}$ of modified sequencing grade trypsin (Promega) in $50 \mathrm{mM}$ ammonium bicarbonate overnight at $37^{\circ} \mathrm{C}$. The resulting peptides were extracted in $50 \mathrm{mM}$ ammonium bicarbonate followed by $10 \%$ formic acid/acetonitrile $(1 / 1 \mathrm{v} / \mathrm{v})$. The peptidic fractions were dried under speed-vacuum and resuspended with $5 \%$ acetonitrile, $0.05 \%$ trifluoroacetic acid (TFA) for MS analysis.

Peptides were analyzed by nanoLC-MS/MS using an UltiMate 3000 RSLCnano system coupled to a Q-Exactive Plus mass spectrometer (Thermo Fisher Scientific, Bremen, Germany). Five $\mu \mathrm{L}$ of each sample were loaded on a C-18 precolumn (300 $\mu \mathrm{m}$ ID x $5 \mathrm{~mm}$, Thermo Fisher) in a solvent made of $5 \%$ acetonitrile and $0.05 \%$ TFA and at a flow rate of $20 \mu \mathrm{L} / \mathrm{min}$. After 5 min of desalting, the precolumn was switched online with the analytical C-18 column ( $75 \mu \mathrm{m}$ ID x $15 \mathrm{~cm}$, Reprosil C18) equilibrated in $95 \%$ solvent A (5\% acetonitrile, $0.2 \%$ formic acid) and $5 \%$ solvent B ( $80 \%$ acetonitrile, $0.2 \%$ formic acid). Peptides were eluted using a 5 to $50 \%$ gradient of solvent B over $300 \mathrm{~min}$ at a flow rate of $300 \mathrm{~nL} / \mathrm{min}$. The Q-Exactive Plus was operated in a data-dependent acquisition mode with the XCalibur software. MS survey scans were acquired in the Orbitrap on the 350-1500 m/z range with the resolution set to a value of 70000 . The 10 most intense ions per survey scan were selected for HCD fragmentation and the resulting fragments were analyzed in the Orbitrap with the resolution set to a value of 17500 . Dynamic exclusion was employed within 30 seconds to prevent repetitive selection of the same peptide. Duplicate technical LC-MS measurements were performed for each sample.

Raw mass spectrometry files were processed with the MaxQuant software (version 1.6.3.4) for database search with the Andromeda search engine and quantitative analysis. Data were searched against human entries of the Swissprot protein database (UniProtKB/Swiss-Prot Knowledgebase release 2018_02). Carbamidomethylation of 
cysteines was set as a fixed modification whereas oxidation of methionine and protein $\mathrm{N}$-terminal acetylation were set as variable modifications. Specificity of trypsin digestion was set for cleavage after $\mathrm{K}$ or $\mathrm{R}$, and two missed trypsin cleavage sites were allowed. The precursor mass tolerance was set to $20 \mathrm{ppm}$ for the first search and $4.5 \mathrm{ppm}$ for the main Andromeda database search. The mass tolerances MS/MS mode was set to 0.5 Da. Minimum peptide length was set to seven amino acids, and minimum number of unique peptides was set to one. Andromeda results were validated by the target-decoy approach using a reverse database at both a peptide and a protein FDR of $1 \%$. For label-free relative quantification of the samples, the "match between runs" option of MaxQuant was enabled with a time window of $0.7 \mathrm{~min}$, to allow cross-assignment of MS features detected in the different runs.

The "LFQ" metric from the MaxQuant "protein group.txt" output was used to quantify proteins. Missing protein intensity values were replaced by a constant noise value determined independently for each sample as the lowest value of the total protein population. Only proteins identified in at least three samples in the same location (i.e. SC-Ad or BM-Ad) were considered as robustly detected and were used for statistical and bioinformatic analyses. Protein involved in lipid and glucose metabolism were selected using gene analytics software based on their involvement into the following pathways: Regulation of lipid metabolism; Insulin signaling-generic cascades; Lipoprotein metabolism; Adipogenesis; Regulation of lipid metabolism by Peroxisome proliferator-activated receptor alpha; Glucose / Energy Metabolism; Peroxisomal lipid metabolism; Calcium (Ca), cyclic adenosine monophosphate (cAMP) and Lipid Signaling; Nuclear Receptors in Lipid Metabolism and Toxicity; SREBF (Sterol Regulatory Element Binding Protein Gene) and miR33 in cholesterol and lipid homeostasis; Acyl chain remodeling of Phospho Ethanolamine (PE) ; Cholesterol and Sphingolipids transport / Distribution to the intracellular membrane compartments; Synthesis of substrates in N-glycan biosynthesis; Synthesis of Phosphatidyl Choline (PC); Metabolism of steroid hormones; Glycerophospholipid biosynthesis; Glucose metabolism; Fat digestion and absorption; Regulation of cholesterol biosynthesis by SREBP (Sterol Regulatory Element Binding Protein); cholesterol biosynthesis III (via desmosterol); Cholesterol and Sphingolipids transport / Transport from Golgi and ER to the apical membrane; Aldosterone synthesis and secretion; Citrate cycle (Tricarboxylic Acid (TCA) cycle); Adipocytokine signaling pathway; Sphingolipid metabolism; Fatty acid metabolism; Pyruvate metabolism; Arachidonic acid metabolism; Linoleic acid metabolism; Ceramide Pathway; Sphingolipid signaling pathway; sphingomyelin metabolism/ceramide salvage; Pentose phosphate pathway; Regulation of lipolysis in adipocytes; Mitochondrial Long Chain-Fatty Acid, Beta-Oxidation SuperPath; Fatty acid biosynthesis. Among the 1948 proteins retrieved by the database, we robustly identified 612 proteins. The label free quantification (LFQ) intensity for each identified protein was $\log 2$ transformed and used to perform the principal component analysis with R software (v3.5) and FactomineR package. The statistical analysis of differentially expressed proteins was performed with LIMMA package from Bioconductor using linear model followed by borrowing strength across protein with empirical bays methods with a design matrix build on two groups (BM-Ad and SC-Ad) (see Supplementary Table 1). The protein expression was considered significantly different if the p-value was lower than 0.05. Pathway enrichment analysis was performed with gene analytics software. The official gene symbol of the proteins significantly enriched or down-regulated was used as entry to determine the pathways enriched or downregulated respectively. The heatmaps and associated hierarchical clustering build on K-means methods were resolved with $\mathrm{R}$ and ggplot2 package. 


\section{In vitro adipogenesis}

The pre-adipocyte 3T3 F442A obtained from ECACC (00070654) were grown and differentiated into adipocyte as previously described (Meulle et al, 2008). OP9 cell were obtained from ATCC (ATCC CRL-2749). OP9 cells were seeded at $1 \times 10^{5}$ cell/well in 6-well plates for 2 days in MEM alpha supplemented with $20 \%$ fetal calf serum (FCS), $125 \mathrm{mg} / \mathrm{mL}$ streptomycin, $125 \mathrm{UI} / \mathrm{mL}$ penicillin. At $80 \%$ of confluence, media was replaced with similar media supplemented with $15 \%$ knock-out serum (invitrogen10828-028) for 5 days to induce adipogenic differentiation (Wolins et al, 2006). Human BM-MSC were isolated from bone marrow (obtained by sternal puncture) of healthy patients as previously described (Corre et al, 2007). BM-MSC (passage 2) were seeded at $3 \times 10^{5}$ cell/well in 6-well plates for 2 days in MEM alpha supplemented with $10 \%$ fetal calf serum (FCS), $125 \mathrm{mg} / \mathrm{mL}$ streptomycin, $125 \mathrm{UI} / \mathrm{mL}$ penicillin. At $80 \%$ of confluence, media was replaced with StemMACS AdipoDiff Media (Miltenyi 130-091-677) supplemented with $125 \mathrm{mg} / \mathrm{mL}$ streptomycin, $125 \mathrm{UI} / \mathrm{mL}$ penicillin to induce adipogenic differentiation for 28 days. Media was changed every 2 to 3 days and cells were grown in a humid atmosphere with $5 \% \mathrm{CO} 2$ at $37^{\circ} \mathrm{C}$. TG content of cells before and at the end of adipogenic differentiation was performed as previously described (Dirat et al, 2011) using commercial kit (Sigma- F6428).

\section{Western blot}

Isolated adipocytes were washed 3 times with PBS and proteins were separated from lipids using MTBE extraction described above (proteomic analysis section). Five $\mu \mathrm{g}$ of proteins were reduced with modified Laemmli buffer for 15 minutes at $65^{\circ} \mathrm{C}$, loaded on $4-10 \%$ gradient SDS-PAGE gel (Biorad) and transferred to nitrocellulose membrane. Membranes were blocked with $5 \%$ skimmed milk in TBS $(20 \mathrm{mM}$ Tris, $150 \mathrm{mM} \mathrm{NaCl})$ and incubated with appropriate primary antibodies (rabbit polyclonal antibody (pAb) anti ATGL, (1/:1000, ref: 2138, Cell Signaling Technology); rabbit pAb anti HSL (1:1000, ref: 4107, Cell Signaling Technology); rabbit pAb anti MAGL (1:1000, ref: sc134749, Santa Cruz Biotechnology); mouse monoclonal anti $\beta$-Actin (1:5000, clone: AC15, Sigma Aldrich). The membranes were washed with TBS complemented with $0.1 \%$ Tween-20 and incubated with HRP conjugated secondary antibodies (1:5000, Santacruz Biotechnology). The immunoreactive protein bands were revealed by ECL prime Western blotting detection reagent $\left(\mathrm{Ammersham}^{\mathrm{TM}}\right)$ and detected using ChemiDoc ${ }^{\mathrm{TM}}$ Imaging System (Biorad). Densitometry quantification was performed using image lab software (v5.2.1; Biorad). Signal intensity was normalized to $\beta$-Actin.

\section{Lipolysis assay}

Isolated adipocytes $(50 \mu \mathrm{l})$ were incubated with $450 \mu \mathrm{L} \mathrm{KRBHA}$ with or without isoprenaline $10^{-6} \mathrm{~mol}^{\mathrm{L}} \mathrm{L}^{-1}$ (Sigma Aldrich) to evaluate stimulated and basal lipolysis respectively. After $2 \mathrm{~h}$ incubation at $37^{\circ} \mathrm{C}$ under gentle shaking, $200 \mu \mathrm{L}$ of incubation media was removed and kept to measure glycerol and FA release using commercial kits (Sigma- F6428 and Wako diagnostic NEFA-HR, respectively). Results were normalized to total lipid content quantified after Dole extraction. Briefly, isolated adipocytes were lysed by the addition of Dole's Reagent (40:10:1 isopropanol : heptane : $\mathrm{H}_{2} \mathrm{SO}_{4} 1 \mathrm{~N}$ ). Upper phase containing lipids was extracted again with heptane, evaporated under a nitrogen stream and dried lipids were weighted. For lipolysis experiment on adipocyte-differentiated cell lines (3T3 F442A and OP9) and human BM-MSC, cells were incubated for 3 hours and results were normalized to TG content. At the end of the incubation, cells were washed with PBS and resuspended in buffer containing $10 \mathrm{mM}$ Tris HCL pH 7.5 and $1 \mathrm{mM}$ EDTA to quantify TG. 


\section{Statistical analyses}

Statistical analyses were performed using Prism v4 (GraphPad Software). Comparison between two groups was performed using paired Student's t-test and multiple comparisons was performed by two-way ANOVA follow by Bonferroni post-test for $\mathrm{n}$ independent experiments. P-value was considered significant if lower than 0.05 .

\section{Acknowledgements}

This work benefited from the assistance of Stephanie Balor and Vanessa Soldan from the Multiscale Electron Imaging platform (METi) of the Centre de Biologie Intégrative (Toulouse, France). Lipidomic analysis was performed at the Mass Spectrometry Facility of the Beth Israel Deaconess Medical Center (Boston, USA). This work by supported by the "Fondation de France (contract $\mathrm{N}^{\circ}$ 171352) for running costs and a two-year postdoctoral fellowship for Camille Attané. David Estève received a post-doctoral fellowship from the Fondation pour La Recherche Médicale (SPF201809007124). This work also benefited from the Toulouse Réseau Imagerie (TRI)RIO Optical Imaging Platform at the Institute of Pharmacology and Structural Biology (Genotoul, Toulouse, France) supported by grants from the Région Midi-Pyrénées (contrat de projets état-région), the Grand Toulouse community, the Association pour la Recherche sur le Cancer (Equipement 8505), the CNRS and the European Union through the Fonds Européen de Développement Régional program. We thank Life Science Editors for editorial assistance.

\section{Author contributions}

NR set up the conditions for harvesting BM-AT and SC-AT in close collaboration with CA and DE and supervised the samples collection. CA, DE, MM handled the AT samples and isolated adipocytes. DE performed the transmission electron microscopy (with the help of the METi platform) and the immunofluorescence experiments as well as image data analysis. CA performed sample preparation for proteomic and lipidomic studies, Western blot, cell culture (with the help of MM) and the lipolysis experiments. JC performed the isolation of human BMMSC. KC performed the proteomics studies under the supervision of OS. DE and CA conducted analysis of lipidomic (with the help of PV) and proteomic data under the supervision of JI. CA, DE, PV, OS and CM analyzed the data. CA, DE and CM conceived the idea for this project and wrote the manuscript with significant inputs from all authors. CM supervised the study.

\section{Conflict of interest}

The authors declare they have no conflict of interest 
bioRxiv preprint doi: https://doi.org/10.1101/641886; this version posted May 19, 2019. The copyright holder for this preprint (which was not certified by peer review) is the author/funder. All rights reserved. No reuse allowed without permission.

\section{References}

Abella E, Feliu E, Granada I, Milla F, Oriol A, Ribera JM, Sanchez-Planell L, Berga LI, Reverter JC, Rozman C (2002) Bone marrow changes in anorexia nervosa are correlated with the amount of weight loss and not with other clinical findings. American Journal of Clinical Pathology 118: 582-588

Bartelt A, Heeren J (2014) Adipose tissue browning and metabolic health. Nature Reviews Endocrinology 10: 2436

Bathija A, Davis S, Trubowitz S (1979) Bone marrow adipose tissue: response to acute starvation. American Journal of Hematology 6: 191-198

Bredella MA, Torriani M, Ghomi RH, Thomas BJ, Brick DJ, Gerweck AV, Rosen CJ, Klibanski A, Miller KK (2010) Vertebral Bone Marrow Fat Is Positively Associated With Visceral Fat and Inversely Associated With IGF1 in Obese Women. Obesity 19: 49-53

Breitkopf SB, Ricoult SJH, Yuan M, Xu Y, Peake DA, Manning BD, Asara JM (2017) A relative quantitative positive/negative ion switching method for untargeted lipidomics via high resolution LC-MS/MS from any biological source. Metabolomics : Official Journal of the Metabolomic Society 13

Cawthorn William P, Scheller Erica L, Learman Brian S, Parlee Sebastian D, Simon Becky R, Mori H, Ning X, Bree Adam J, Schell B, Broome David T, Soliman Sandra S, DelProposto Jenifer L, Lumeng Carey N, Mitra A, Pandit Sandeep V, Gallagher Katherine A, Miller Joshua D, Krishnan V, Hui Susanta K, Bredella Miriam A, Fazeli Pouneh K, Klibanski A, Horowitz Mark C, Rosen Clifford J, MacDougald Ormond A (2014) Bone Marrow Adipose Tissue Is an Endocrine Organ that Contributes to Increased Circulating Adiponectin during Caloric Restriction. Cell Metabolism 20: 368-375

Cawthorn WP, Scheller EL, Parlee SD, Pham HA, Learman BS, Redshaw CMH, Sulston RJ, Burr AA, Das AK, Simon BR, Mori H, Bree AJ, Schell B, Krishnan V, MacDougald OA (2016) Expansion of Bone Marrow Adipose Tissue During Caloric Restriction Is Associated With Increased Circulating Glucocorticoids and Not With Hypoleptinemia. Endocrinology 157: 508-521

Cinti S (2001) The adipose organ: morphological perspectives of adipose tissues. The Proceedings of the Nutrition Society 60: $319-328$

Corre J, Mahtouk K, Attal M, Gadelorge M, Huynh A, Fleury-Cappellesso S, Danho C, Laharrague P, Klein B, Reme T, Bourin P (2007) Bone marrow mesenchymal stem cells are abnormal in multiple myeloma. Leukemia 21: $1079-1088$

Devlin MJ, Cloutier AM, Thomas NA, Panus DA, Lotinun S, Pinz I, Baron R, Rosen CJ, Bouxsein ML (2010) Caloric restriction leads to high marrow adiposity and low bone mass in growing mice. Journal of Bone and Mineral Research 25: 2078-2088

Diedrich JD, Rajagurubandara E, Herroon MK, Mahapatra G, Huttemann M, Podgorski I (2016) Bone marrow adipocytes promote the Warburg phenotype in metastatic prostate tumors via HIF-1alpha activation. Oncotarget 7: $64854-64877$

Dirat B, Bochet L, Dabek M, Daviaud D, Dauvillier S, Majed B, Wang YY, Meulle A, Salles B, Le Gonidec S, Garrido I, Escourrou G, Valet P, Muller C (2011) Cancer-associated adipocytes exhibit an activated phenotype and contribute to breast cancer invasion. Cancer Research 71: 2455-2465

Doucette CR, Horowitz MC, Berry R, MacDougald OA, Anunciado-Koza R, Koza RA, Rosen CJ (2015) A High Fat Diet Increases Bone Marrow Adipose Tissue (MAT) But Does Not Alter Trabecular or Cortical Bone Mass in C57BL/6J Mice. Journal of Cellular Physiology 230: 2032-2037

Fasshauer M, Blüher M (2015) Adipokines in health and disease. Trends in Pharmacological Sciences 36: 461470

Ghali O, Al Rassy N, Hardouin P, Chauveau C (2016) Increased Bone Marrow Adiposity in a Context of Energy Deficit: The Tip of the Iceberg? Frontiers in Endocrinology 7 
bioRxiv preprint doi: https://doi.org/10.1101/641886; this version posted May 19, 2019. The copyright holder for this preprint (which was not certified by peer review) is the author/funder. All rights reserved. No reuse allowed without permission.

Giordano A, Smorlesi A, Frontini A, Barbatelli G, Cinti S (2014) White, brown and pink adipocytes: the extraordinary plasticity of the adipose organ. European journal of Endocrinology 170: R159-171

Hardaway AL, Herroon MK, Rajagurubandara E, Podgorski I (2015) Marrow adipocyte-derived CXCL1 and CXCL2 contribute to osteolysis in metastatic prostate cancer. Clinical \& Experimental Metastasis 32: 353-368

Herroon MK, Rajagurubandara E, Hardaway AL, Powell K, Turchick A, Feldmann D, Podgorski I (2013) Bone marrow adipocytes promote tumor growth in bone via FABP4-dependent mechanisms. Oncotarget 4: 2108-2123

Hindorf C, Glatting G, Chiesa C, Lindén O, Flux G (2010) EANM Dosimetry Committee guidelines for bone marrow and whole-body dosimetry. European Journal of Nuclear Medicine and Molecular Imaging 37: 12381250

Hodson L, Skeaff CM, Fielding BA (2008) Fatty acid composition of adipose tissue and blood in humans and its use as a biomarker of dietary intake. Progress in Lipid Research 47: 348-380

Justesen J, Stenderup K, Ebbesen EN, Mosekilde L, Steiniche T, Kassem M (2001) Adipocyte tissue volume in bone marrow is increased with aging and in patients with osteoporosis. Biogerontology 2: 165-171

Kim SH, Cho KW, Choi HS, Park SJ, Rhee Y, Jung HS, Lim SK (2009) The forkhead transcription factor Foxc2 stimulates osteoblast differentiation. Biochemical and Biophysical Research Communications 386: 532-536

Krings A, Rahman S, Huang S, Lu Y, Czernik PJ, Lecka-Czernik B (2012) Bone marrow fat has brown adipose tissue characteristics, which are attenuated with aging and diabetes. Bone 50: 546-552

Lafontan M, Langin D (2009) Lipolysis and lipid mobilization in human adipose tissue. Progress in Lipid Research 48: 275-297

Lee MJ, Fried SK (2014) Optimal protocol for the differentiation and metabolic analysis of human adipose stromal cells. Methods in Enzymology 538: 49-65

Leitner BP, Huang S, Brychta RJ, Duckworth CJ, Baskin AS, McGehee S, Tal I, Dieckmann W, Gupta G, Kolodny GM, Pacak K, Herscovitch P, Cypess AM, Chen KY (2017) Mapping of human brown adipose tissue in lean and obese young men. Proceedings of the National Academy of Sciences of the United States of America 114: 86498654

Litvinov DY, Savushkin EV, Dergunov AD (2018) Intracellular and Plasma Membrane Events in Cholesterol Transport and Homeostasis. Journal of Lipids 2018: 3965054

Liu Z, Xu J, He J, Liu H, Lin P, Wan X, Navone NM, Tong Q, Kwak LW, Orlowski RZ, Yang J (2015) Mature adipocytes in bone marrow protect myeloma cells against chemotherapy through autophagy activation. Oncotarget 6: $34329-34341$

Mattiucci D, Maurizi G, Izzi V, Cenci L, Ciarlantini M, Mancini S, Mensà E, Pascarella R, Vivarelli M, Olivieri A, Leoni P, Poloni A (2018) Bone marrow adipocytes support hematopoietic stem cell survival. Journal of Cellular Physiology 233: 1500-1511

Meulle A, Salles B, Daviaud D, Valet P, Muller C (2008) Positive regulation of DNA double strand break repair activity during differentiation of long life span cells: the example of adipogenesis. PLoS One 3: e3345

Naveiras O, Nardi V, Wenzel PL, Hauschka PV, Fahey F, Daley GQ (2009) Bone-marrow adipocytes as negative regulators of the haematopoietic microenvironment. Nature 460: 259-263

Nedergaard J, Bengtsson T, Cannon B (2007) Unexpected evidence for active brown adipose tissue in adult humans. Am J Physiol Endocrinol Metab 293: E444-452

Ninomiya Y, Sugahara-Yamashita Y, Nakachi Y, Tokuzawa Y, Okazaki Y, Nishiyama M (2010) Development of a rapid culture method to induce adipocyte differentiation of human bone marrow-derived mesenchymal stem cells. Biochemical and Biophysical Research Communications 394: 303-308 
bioRxiv preprint doi: https://doi.org/10.1101/641886; this version posted May 19, 2019. The copyright holder for this preprint (which was not certified by peer review) is the author/funder. All rights reserved. No reuse allowed without permission.

Nishikata I, Nakahata S, Saito Y, Kaneda K, Ichihara E, Yamakawa N, Morishita K (2011) Sumoylation of MEL1S at lysine 568 and its interaction with CtBP facilitates its repressor activity and the blockade of G-CSF-induced myeloid differentiation. Oncogene 30: 4194-4207

Prentice KJ, Saksi J, Hotamisligil GS (2019) Adipokine FABP4 integrates energy stores and counter regulatory metabolic responses. Journal of Lipid Research

Robles H, Park S, Joens MS, Fitzpatrick JAJ, Craft CS, Scheller EL (2019) Characterization of the bone marrow adipocyte niche with three-dimensional electron microscopy. Bone 118: 89-98

Saito M, Okamatsu-Ogura Y, Matsushita M, Watanabe K, Yoneshiro T, Nio-Kobayashi J, Iwanaga T, Miyagawa M, Kameya T, Nakada K, Kawai Y, Tsujisaki M (2009) High incidence of metabolically active brown adipose tissue in healthy adult humans: effects of cold exposure and adiposity. Diabetes 58: 1526-1531

Scheller EL, Cawthorn WP, Burr AA, Horowitz MC, MacDougald OA (2016) Marrow Adipose Tissue: Trimming the Fat. Trends in Endocrinology and Metabolism 27: 392-403

Scheller EL, Doucette CR, Learman BS, Cawthorn WP, Khandaker S, Schell B, Wu B, Ding SY, Bredella MA, Fazeli PK, Khoury B, Jepsen KJ, Pilch PF, Klibanski A, Rosen CJ, MacDougald OA (2015) Region-specific variation in the properties of skeletal adipocytes reveals regulated and constitutive marrow adipose tissues. Nature Communications 6: 7808

Scheller EL, Khandaker S, Learman BS, Cawthorn WP, Anderson LM, Pham HA, Robles H, Wang Z, Li Z, Parlee SD, Simon BR, Mori H, Bree AJ, Craft CS, MacDougald OA (2019) Bone marrow adipocytes resist lipolysis and remodeling in response to beta-adrenergic stimulation. Bone 118: 32-41

Scheller EL, Rosen CJ (2014) What's the matter with MAT? Marrow adipose tissue, metabolism, and skeletal health. Ann N Y Acad Sci 1311: 14-30

Schreibman PH, Dell RB (1975) Human adipocyte cholesterol. Concentration, localization, synthesis, and turnover. The Journal of Clinical Investigation 55: 986-993

Scott MA, Nguyen VT, Levi B, James AW (2011) Current methods of adipogenic differentiation of mesenchymal stem cells. Stem Cells and Development 20: 1793-1804

Shafat MS, Oellerich T, Mohr S, Robinson SD, Edwards DR, Marlein CR, Piddock RE, Fenech M, Zaitseva L, Abdul-Aziz A, Turner J, Watkins JA, Lawes M, Bowles KM, Rushworth SA (2017) Leukemic blasts program bone marrow adipocytes to generate a protumoral microenvironment. Blood 129: 1320-1332

Tabe Y, Yamamoto S, Saitoh K, Sekihara K, Monma N, Ikeo K, Mogushi K, Shikami M, Ruvolo V, Ishizawa J, Hail N, Kazuno S, Igarashi M, Matsushita H, Yamanaka Y, Arai H, Nagaoka I, Miida T, Hayashizaki Y, Konopleva M, Andreeff M (2017) Bone Marrow Adipocytes Facilitate Fatty Acid Oxidation Activating AMPK and a Transcriptional Network Supporting Survival of Acute Monocytic Leukemia Cells. Cancer Research 77: 1453-1464

Taschler U, Radner FP, Heier C, Schreiber R, Schweiger M, Schoiswohl G, Preiss-Landl K, Jaeger D, Reiter B, Koefeler HC, Wojciechowski J, Theussl C, Penninger JM, Lass A, Haemmerle G, Zechner R, Zimmermann R (2011) Monoglyceride lipase deficiency in mice impairs lipolysis and attenuates diet-induced insulin resistance. The Journal of Biological Chemistry 286: 17467-17477

Tavassoli M (1974) Differential response of bone marrow and extramedullary adipose cells to starvation. Experientia 30: 424-425

Wen PC, Mahinthichaichan P, Trebesch N, Jiang T, Zhao Z, Shinn E, Wang Y, Shekhar M, Kapoor K, Chan CK, Tajkhorshid E (2018) Microscopic view of lipids and their diverse biological functions. Current Opinion in Structural Biology 51: 177-186 
bioRxiv preprint doi: https://doi.org/10.1101/641886; this version posted May 19, 2019. The copyright holder for this preprint (which was not certified by peer review) is the author/funder. All rights reserved. No reuse allowed without permission.

Wolins NE, Quaynor BK, Skinner JR, Tzekov A, Park C, Choi K, Bickel PE (2006) OP9 mouse stromal cells rapidly differentiate into adipocytes: characterization of a useful new model of adipogenesis. Journal of Lipid Research 47: 450-460

Wu J, Bostrom P, Sparks LM, Ye L, Choi JH, Giang AH, Khandekar M, Virtanen KA, Nuutila P, Schaart G, Huang K, Tu H, van Marken Lichtenbelt WD, Hoeks J, Enerback S, Schrauwen P, Spiegelman BM (2012) Beige adipocytes are a distinct type of thermogenic fat cell in mouse and human. Cell 150: 366-376

Yeung DKW, Griffith JF, Antonio GE, Lee FKH, Woo J, Leung PC (2005) Osteoporosis is associated with increased marrow fat content and decreased marrow fat unsaturation: A proton MR spectroscopy study. Journal of Magnetic Resonance Imaging 22: 279-285

Zechner R (2015) FAT FLUX: enzymes, regulators, and pathophysiology of intracellular lipolysis. EMBO Molecular Medicine 7: 359-362

Zhao S, Mugabo Y, Ballentine G, Attane C, Iglesias J, Poursharifi P, Zhang D, Nguyen Thuy A, Erb H, Prentki R, Peyot M-L, Joly E, Tobin S, Fulton S, Brown JM, Madiraju SRM, Prentki M (2016) $\alpha / \beta$-Hydrolase Domain 6 Deletion Induces Adipose Browning and Prevents Obesity and Type 2 Diabetes. Cell Reports 14: 2872-2888

Zhou BO, Yu H, Yue R, Zhao Z, Rios JJ, Naveiras O, Morrison SJ (2017) Bone marrow adipocytes promote the regeneration of stem cells and haematopoiesis by secreting SCF. Nature Cell Biology 19: 891-903

Zingaretti MC, Crosta F, Vitali A, Guerrieri M, Frontini A, Cannon B, Nedergaard J, Cinti S (2009) The presence of UCP1 demonstrates that metabolically active adipose tissue in the neck of adult humans truly represents brown adipose tissue. FASEB $J$ 23: 3113-3120

Zwick RK, Guerrero-Juarez CF, Horsley V, Plikus MV (2018) Anatomical, Physiological, and Functional Diversity of Adipose Tissue. Cell Metabolism 27: 68-83 


\section{Figure legends}

\section{Fig 1: SC-Ad and BM-Ad exhibit similar morphological properties.}

A. Scheme of the experimental protocol designed to obtain paired human primary bone marrow (BM-Ad) and subcutaneous adipocytes (SC-Ad). Paired bone marrow (BM-AT) and subcutaneous adipose tissues (SC-AT) were harvested from patients undergoing hip replacement surgery. BM-AT, that share the same macroscopic aspects compared to SC-AT, was isolated from the red bone marrow containing hematopoietic cells. After enzymatic digestion, floating cells were rinsed and collected for subsequent experiments.

B. Whole mount SC-AT and BM-AT were stained with Bodipy 493/503 (neutral lipids, green), Phalloidin (FActin, red) and TOPRO-3 (nucleus, blue). $\mathrm{Z}$ stack images were taken using confocal microscope with 10X objective $(\mathrm{n}=3)$. Representative maximum intensity projection is shown. Orange arrowheads show vessels. White arrowheads show stromal cells. Scale bar, $100 \mu \mathrm{m}$.

C. Transmission electron microscopy images of SC-AT and BM-AT. N: Nucleus, LD: Lipid Droplet, C: cytoplasm. Scale bar, $0.5 \mu \mathrm{m}$.

D. Primary SC-Ad and BM-Ad were isolated and stained with Bodipy 493/503 (neutral lipids, green), phalloidin (F-actin, red) and TOPRO3 (nucleus, blue). Z stack images were taken using confocal microscope with 40X objective $(n=3)$. Representative maximum intensity projection is shown. Scale bar, $50 \mu \mathrm{m}$.

Fig 2: Detailed lipid species analysis of BM-Ad shows increase free cholesterol and MG contents compared to SC-Ad.

A. Total lipid content in SC-AT and BM-AT (left, n=7) and in SC-Ad and BM-Ad (right, n=17) were extracted and weighted. The quantity of lipids was normalized to the quantity of tissue or the volume of adipocyte from which lipids were extracted. Histograms represent mean \pm SEM. ns stands for non-significant according to paired $\mathrm{t}$ test.

B. Pie chart of the relative abundance of the detected lipid classes using large-scale LC-MS/MS approaches. The glycerolipids (GL) are shown in blue shades. TG: triacylglycerol, DG: diacylglycerol, MG: monoacylglycerol; Phospholipids (PL) are in green shades. PC: phosphatidylcholine, PE: Phosphatidylethanolamine, PG: phosphatidylglycerol, PI: Phostatidylinositol, PS: Phosphatidylserine, LPC: Lysophosphatidylcholine, LPE: Lysophosphatidylethanolamine, Sphingolipids (SL) are in yellow shades. SM: Sphingomyeline, Cer: Ceramides, So: Sphingosine; and fatty acid esters (FAE) are in pink shades. WE: Wax Ester, AcCA: Acyl Carnitine.

C. Violin plot representing the $\log 2$ fold change of the 15 lipid classes identified in BM-Ad compared to SC-Ad analyzed by LC-MS/MS $(n=4)$. The quantity of lipid classes were calculated as the sum of the different lipid species belonging to the same classes.

D: Free cholesterol contents were measured using an enzymatic assay on lipid extracted from BM-Ad and SC-Ad. The results were normalized to the quantity of total lipids. The histograms represent mean $\pm \mathrm{SEM},{ }^{* * *} \mathrm{p}<0.001$ according to paired $\mathrm{t}$ test $(\mathrm{n}=11)$.

Fig 3: Large-scale proteome analysis highlights differences in lipid metabolism between BM-Ad and SCAd. 
A. Principal component analysis of BM-Ad (grey) and SC-Ad (black) based on the relative quantification of the abundance of the proteins involved in lipid and glucose metabolism identified in the LC-MS/MS dataset. The first two components and the percentage of variance for each component are shown. Ellipses show the $95 \%$ confidence are interval to strengthen the clustering of the tissues according to their anatomical locations.

B. Volcano plot of the 612 proteins involved in lipid and glucose metabolism identified and quantified using LCMS/MS analysis. Sixty seven proteins are significantly $(\mathrm{p}<0.05)$ enriched in BM-Ad (red circles), whereas 68 proteins are significantly $(p<0.05)$ down-regulated (blue circle) and 477 are unmodified (open circle) in BM-Ad compared to SC-Ad according to linear model statistical analysis.

$$
\text { C. Pathway enrichment analysis performed with gene analytics. The top pathways enriched in BM-Ad (red bars) }
$$
and down-regulated (blue bars) are presented.

D. Heatmap of the relative abundance of proteins differentially expressed in BM-Ad and SC-Ad belonging to the lipoprotein metabolism pathway. Dendrogram represents hierarchical clustering of the samples. Blue squares represent down regulated proteins and red squares enriched proteins.

Fig 4: Human native BM-Ad are devoid of lipolytic activity, a metabolic trait not recapitulated by primary BM-MSCs differentiated in vitro.

A. Left panel: Western blot analyses of the three main enzymes involved in lipolysis on paired isolated SC-Ad (SC) and BM-Ad (M) from 3 independent donors. $\beta$-actin is shown as loading control. Right panel: relative quantifications of the band intensity normalized to the quantity of $\beta$-actin. The histograms represent mean $\pm \operatorname{SEM}$. ns $=$ not significant. $* * \mathrm{p}<0.01$ according to paired Student's t-test.

B. Glycerol release was measured from isolated SC-Ad and BM-Ad as readout of complete lipolysis under basal condition (plain bar) or after stimulation with isoprenaline (hatched bar). The data are mean of 7 independent experiments and normalized to the quantity of the total lipids content. The histograms represent mean \pm SEM, ns, not significant; $* * * p<0.001$ according to two-way ANOVA followed by Bonferroni post-test.

C. Free fatty acids (FFA) release from isolated SC-Ad and BM-Ad as readout of lipolysis under basal condition (plain bar) or after stimulation with isoprenaline (hatched bar). Data are mean of 7 independent experiments and are normalized to the quantity of the total lipids content. The histograms represent mean \pm SEM, ns, not significant; $* * \mathrm{p}<0.01$ according to two-way ANOVA followed by Bonferroni post-test.

D. TG content was measured in cell lysates from 3T3F442A (3T3) and OP9 cell lines or human BM-MSC (MSC) before and after adipogenic differentiation (nd: non-differentiated, d: differentiated). Data are mean of at least 4 independent experiments (4 independent donors were used for human BM-MSC) and were normalized to the quantity of the total protein content. The histograms represent mean $\pm \mathrm{SEM},{ }^{*} \mathrm{p}<0.05 ;{ }^{*} \mathrm{p}<0.01$ according to twoway ANOVA followed by Bonferroni post-test

E. Glycerol release from in vitro differentiated 3T3F442A (3T3) and OP9 cell lines or human BM-MSC (MSC) as readout of complete lipolysis under basal conditions (plain bar) or after stimulation with isoprenaline (hatched bar). The data are mean of 3 independent experiments ( 3 independent donors were used for human BM-MSC) and were normalized to the quantity of the total lipids content. The histograms represent mean $\pm \mathrm{SEM},{ }^{*} \mathrm{p}<0.05$; $* * \mathrm{p}<0.01$ according to two-way ANOVA followed by Bonferroni post-test. 


\section{Expanded View Figure legends}

\section{Fig EV1: SC-Ad and BM-Ad exhibit similar morphology}

A. Whole mount SC-AT and BM-AT were stained with an antibody directed against perilipin 1 (PLIN1, green), phalloidin (F-Actin, red) and TOPRO-3 (nucleus, blue). Z stack images were taken using confocal microscope with $40 X$ objective $(n=3)$. Representative maximum intensity projection is shown. Orange arrowheads show vessels and white arrowheads show stromal cells. Scale bar $=50 \mu \mathrm{m}$.

B. Representative XY and YZ focal planes are shown to highlight the cohesive organization of the SC- and BMAT and the thin cytoplasm of adipocytes (blue arrowheads).

Fig EV2: Unsupervised lipidomic analyses reveal that the variance between samples mainly occur through inter-individual variability despite increased MG species in BM-Ad.

A. Principal component analysis of BM-Ad (grey) and SC-Ad (black) based on the relative quantification of the lipid species identified in LC-MS/MS. The first two components and the percentage of variance for each component are shown.

B. Heatmap of the relative abundance of lipid species quantified in BM-Ad and SC-Ad. Dendrogram represents hierarchical clustering of samples. Blue squares represent down-regulated lipid species and red squares enriched lipid species.

C. Relative quantification of the main MG species by LC-MS/MS in paired isolated SC-Ad and BM-Ad ( $\mathrm{n}=4)$. Histograms represent mean $\pm \mathrm{SEM}, * \mathrm{p}<0.05$ according to two way ANOVA followed by Bonferroni’s post-test.

Fig EV3. Large-scale analysis of the proteome reveals differences in lipid metabolism, but not adipokines, between BM-Ad and SC-Ad.

A. Scheme of the proteomic dataset analysis workflow. Extracted proteins from paired isolated SC-and BM-Ad were analyzed by LC-MS/MS. Among the 3787 proteins identified, 3259 were robustly identified in at least 3 of 4 donors. We selected a set of 612 proteins involved in lipid and glucose metabolism using gene analytics software to perform the statistical and bioinformatics analyses. In this dataset, unsupervised multivariate analysis was performed and differentially expressed proteins were identified using a linear statistical model (LIMMA) allowing to identify 67 proteins enriched and 68 proteins downregulated in BM-Ad compared to SC-Ad. Pathway enrichment analyses were performed using gene analytics software that concatenates several databases to identify specific lipid pathways enriched and down regulated in BM-Ad. Hierarchical clustering analyses were then performed on these specific lipid pathways.

B. Heatmap of the relative abundance of adipokines expressed in BM-Ad and SC-Ad. Dendrogram represents hierarchical clustering of the samples. Blue squares represents down regulated proteins and red squares enriched proteins.

C. Heatmaps of the relative abundance of proteins differentially expressed in BM-Ad and SC-Ad belonging to the Cholesterol Biosynthesis I and Statin pathway. Dendrogram represents hierarchical clustering of the samples. Blue squares represent down regulated proteins and red squares enriched proteins. 
1 D. Heatmap of the relative abundance of proteins differentially expressed in BM-Ad and SC-Ad belonging to the 2 arachidonic acid metabolism pathway. Dendrogram represents hierarchical clustering of the samples. Blue squares 3 represents down regulated proteins and red squares enriched proteins.

4 E. Heatmap of the relative abundance of proteins differentially expressed in BM-Ad and SC-Ad belonging to the 5 FA metabolism pathway. Dendrogram represents hierarchical clustering of the samples. Blue squares represent 6 down regulated proteins. Red squares enriched proteins.

7

\section{Supplementary Table 1:}

9 Protein expression involved in lipid and glucose metabolism were quantified by nano LC-MS/MS. The log2 transformed average intensities of label free quantification (LFQ) in BM-Ad and SC-Ad for each protein in the dataset and the corresponding $\log 2$ fold change and $\mathrm{p}$-Value are presented.

\begin{tabular}{|c|c|c|c|c|}
\hline Gene Symbol & $\begin{array}{l}\text { Average expression in } \\
\text { BM-Ad (log2 LFQ } \\
\text { intensity) }\end{array}$ & $\begin{array}{c}\text { Average expression in } \\
\text { SC-Ad (log2 LFQ } \\
\text { intensity) }\end{array}$ & $\begin{array}{l}\text { log2 Fold change } \\
\text { (BM-Ad / SC-Ad) }\end{array}$ & P.Value \\
\hline S100A4 & 21,510 & 28,158 & $-6,647$ & $7,512 \mathrm{E}-05$ \\
\hline PPP1R1B & 19,924 & 24,015 & $-4,091$ & $1,321 \mathrm{E}-05$ \\
\hline CLPP & 20,921 & 24,880 & $-3,959$ & $4,754 \mathrm{E}-03$ \\
\hline ALDH1A1 & 24,112 & 27,738 & $-3,625$ & $8,082 \mathrm{E}-02$ \\
\hline ALDOC & 25,733 & 29,330 & $-3,598$ & 4,918E-05 \\
\hline SORBS1 & 23,500 & 26,875 & $-3,375$ & $5,411 \mathrm{E}-03$ \\
\hline PEMT & 19,394 & 22,593 & $-3,199$ & $6,775 \mathrm{E}-03$ \\
\hline PHGDH & 24,128 & 27,283 & $-3,155$ & $2,538 \mathrm{E}-02$ \\
\hline VLDLR & 20,088 & 23,180 & $-3,092$ & $6,984 \mathrm{E}-03$ \\
\hline CSNK1G1 & 19,433 & 22,478 & $-3,044$ & $1,903 \mathrm{E}-05$ \\
\hline EIF4B & 21,238 & 24,183 & $-2,945$ & $1,053 \mathrm{E}-03$ \\
\hline PTPRF & 22,233 & 25,150 & $-2,917$ & $2,989 \mathrm{E}-02$ \\
\hline SH3KBP1 & 24,630 & 27,425 & $-2,795$ & $2,680 \mathrm{E}-03$ \\
\hline S100A6 & 26,210 & 28,958 & $-2,748$ & $1,790 \mathrm{E}-03$ \\
\hline ACSS2 & 22,832 & 25,485 & $-2,653$ & $4,720 \mathrm{E}-02$ \\
\hline EIF4H & 22,319 & 24,938 & $-2,618$ & $1,063 \mathrm{E}-02$ \\
\hline UAP1 & 21,296 & 23,913 & $-2,617$ & $1,852 \mathrm{E}-02$ \\
\hline PTGR2 & 21,648 & 24,170 & $-2,522$ & $8,235 \mathrm{E}-03$ \\
\hline TXN2 & 21,132 & 23,585 & $-2,453$ & $2,475 \mathrm{E}-02$ \\
\hline MGLL & 29,233 & 31,678 & $-2,445$ & $2,382 \mathrm{E}-04$ \\
\hline RAB9A & 23,678 & 25,995 & $-2,318$ & $1,546 \mathrm{E}-03$ \\
\hline MAP2K2 & 21,165 & 23,458 & $-2,292$ & $9,283 \mathrm{E}-03$ \\
\hline ME3 & 22,294 & 24,573 & $-2,279$ & $1,045 \mathrm{E}-01$ \\
\hline SYNJ1 & 20,786 & 23,012 & $-2,226$ & $1,832 \mathrm{E}-01$ \\
\hline ACAD11 & 22,650 & 24,873 & $-2,223$ & $8,743 \mathrm{E}-02$ \\
\hline PLIN3 & 25,140 & 27,360 & $-2,220$ & $5,936 \mathrm{E}-02$ \\
\hline ACBD5 & 21,051 & 23,270 & $-2,219$ & $6,033 \mathrm{E}-02$ \\
\hline ACOT2 & 22,473 & 24,650 & $-2,177$ & $1,240 \mathrm{E}-01$ \\
\hline
\end{tabular}




\begin{tabular}{|c|c|c|c|c|}
\hline EXOC7 & 20,732 & 22,880 & $-2,148$ & $2,903 \mathrm{E}-02$ \\
\hline ADH1C & 27,700 & 29,848 & $-2,148$ & $4,060 \mathrm{E}-02$ \\
\hline S100B & 24,340 & 26,405 & $-2,065$ & $1,691 \mathrm{E}-02$ \\
\hline BDH1 & 21,644 & 23,685 & $-2,041$ & 4,369E-02 \\
\hline ENPP1 & 24,585 & 26,575 & $-1,990$ & $3,336 \mathrm{E}-02$ \\
\hline MDH1 & 29,085 & 31,038 & $-1,953$ & $4,880 \mathrm{E}-03$ \\
\hline AKR1C2 & 28,260 & 30,180 & $-1,920$ & $1,803 \mathrm{E}-03$ \\
\hline COPZ2 & 21,636 & 23,480 & $-1,844$ & 2,309E-02 \\
\hline ACADSB & 24,280 & 26,115 & $-1,835$ & $1,092 \mathrm{E}-02$ \\
\hline GCDH & 23,505 & 25,298 & $-1,793$ & 7,491E-02 \\
\hline EPHX2 & 20,757 & 22,510 & $-1,753$ & $5,034 \mathrm{E}-02$ \\
\hline NQO1 & 28,498 & 30,248 & $-1,750$ & $1,928 \mathrm{E}-02$ \\
\hline PTGIS & 21,603 & 23,333 & $-1,729$ & $1,778 \mathrm{E}-01$ \\
\hline PIK3R1 & 20,423 & 22,140 & $-1,717$ & $2,594 \mathrm{E}-02$ \\
\hline MRAS & 25,950 & 27,653 & $-1,703$ & $3,280 \mathrm{E}-03$ \\
\hline AKAP1 & 21,940 & 23,623 & $-1,683$ & $1,381 \mathrm{E}-02$ \\
\hline MCEE & 22,652 & 24,313 & $-1,661$ & $8,804 \mathrm{E}-02$ \\
\hline TOMM20 & 21,184 & 22,798 & $-1,614$ & $3,009 \mathrm{E}-02$ \\
\hline PLIN1 & 34,325 & 35,935 & $-1,610$ & $1,040 \mathrm{E}-02$ \\
\hline PCYT2 & 22,651 & 24,243 & $-1,592$ & $1,259 \mathrm{E}-01$ \\
\hline RELA & 25,958 & 27,548 & $-1,590$ & $7,966 \mathrm{E}-03$ \\
\hline DDHD2 & 20,702 & 22,280 & $-1,578$ & $3,466 \mathrm{E}-02$ \\
\hline ACAT1 & 29,143 & 30,708 & $-1,565$ & $6,936 \mathrm{E}-03$ \\
\hline ANXA1 & 31,820 & 33,375 & $-1,555$ & $9,500 \mathrm{E}-03$ \\
\hline CBR3 & 23,495 & 25,018 & $-1,523$ & $5,170 \mathrm{E}-02$ \\
\hline GBE1 & 27,890 & 29,398 & $-1,508$ & $1,802 \mathrm{E}-02$ \\
\hline PRDX6 & 30,043 & 31,543 & $-1,500$ & $2,034 \mathrm{E}-02$ \\
\hline PYGB & 26,510 & 27,990 & $-1,480$ & $6,462 \mathrm{E}-02$ \\
\hline TNFAIP8 & 21,773 & 23,248 & $-1,475$ & $5,419 \mathrm{E}-02$ \\
\hline AKR1C3 & 27,375 & 28,843 & $-1,467$ & $1,787 \mathrm{E}-02$ \\
\hline ARSA & 21,528 & 22,990 & $-1,463$ & $3,140 \mathrm{E}-02$ \\
\hline GNPDA2 & 20,600 & 22,058 & $-1,457$ & $3,903 \mathrm{E}-02$ \\
\hline TKT & 30,495 & 31,950 & $-1,455$ & $1,336 \mathrm{E}-02$ \\
\hline ACAD9 & 28,818 & 30,255 & $-1,438$ & $1,406 \mathrm{E}-01$ \\
\hline PDE3B & 21,590 & 23,023 & $-1,433$ & $8,953 \mathrm{E}-02$ \\
\hline EIF2B3 & 19,956 & 21,368 & $-1,411$ & $1,522 \mathrm{E}-01$ \\
\hline CLTA & 23,173 & 24,578 & $-1,405$ & $1,231 \mathrm{E}-01$ \\
\hline ANXA5 & 31,740 & 33,143 & $-1,403$ & $9,549 \mathrm{E}-03$ \\
\hline THRAP3 & 20,393 & 21,785 & $-1,392$ & $1,437 \mathrm{E}-02$ \\
\hline ME1 & 25,840 & 27,218 & $-1,378$ & $1,086 \mathrm{E}-01$ \\
\hline HK2 & 22,870 & 24,243 & $-1,373$ & $2,638 \mathrm{E}-01$ \\
\hline DECR2 & 23,328 & 24,683 & $-1,355$ & $1,035 \mathrm{E}-01$ \\
\hline CRAT & 25,320 & 26,658 & $-1,338$ & $4,616 \mathrm{E}-02$ \\
\hline MPI & 22,198 & 23,528 & $-1,329$ & $1,210 \mathrm{E}-01$ \\
\hline PRKCD & 23,428 & 24,748 & $-1,320$ & $2,517 \mathrm{E}-02$ \\
\hline
\end{tabular}




\begin{tabular}{|c|c|c|c|c|}
\hline SAR1B & 24,960 & 26,275 & $-1,315$ & $1,314 \mathrm{E}-02$ \\
\hline IDH3B & 26,545 & 27,840 & $-1,295$ & $2,022 \mathrm{E}-02$ \\
\hline GRB2 & 23,590 & 24,885 & $-1,295$ & $3,304 \mathrm{E}-01$ \\
\hline EIF2S2 & 26,633 & 27,925 & $-1,292$ & $3,025 \mathrm{E}-02$ \\
\hline CRKL & 22,267 & 23,553 & $-1,286$ & $2,396 \mathrm{E}-01$ \\
\hline ORMDL3 & 23,025 & 24,305 & $-1,280$ & 4,234E-02 \\
\hline LDHA & 29,758 & 31,033 & $-1,275$ & $5,285 \mathrm{E}-02$ \\
\hline VAPB & 25,860 & 27,130 & $-1,270$ & $1,858 \mathrm{E}-02$ \\
\hline DBI & 23,720 & 24,985 & $-1,265$ & $1,730 \mathrm{E}-01$ \\
\hline PDK1 & 21,443 & 22,700 & $-1,257$ & $2,004 \mathrm{E}-01$ \\
\hline GYS1 & 22,526 & 23,778 & $-1,252$ & $3,687 \mathrm{E}-01$ \\
\hline CNTFR & 26,045 & 27,293 & $-1,248$ & $6,133 \mathrm{E}-02$ \\
\hline G6PD & 27,770 & 27,668 & $-1,247$ & $2,904 \mathrm{E}-01$ \\
\hline PGM1 & 28,595 & 29,838 & $-1,243$ & $7,183 \mathrm{E}-02$ \\
\hline GPD1 & 31,363 & 32,605 & $-1,242$ & $5,701 \mathrm{E}-02$ \\
\hline HMOX2 & 24,040 & 25,280 & $-1,240$ & $1,002 \mathrm{E}-02$ \\
\hline ACYP2 & 21,996 & 23,233 & $-1,237$ & $1,044 \mathrm{E}-01$ \\
\hline HADH & 30,430 & 31,653 & $-1,223$ & $2,698 \mathrm{E}-02$ \\
\hline DECR1 & 28,855 & 30,075 & $-1,220$ & $1,758 \mathrm{E}-02$ \\
\hline COPE & 23,085 & 24,305 & $-1,220$ & $1,425 \mathrm{E}-01$ \\
\hline ALG11 & 21,844 & 23,055 & $-1,211$ & $2,749 \mathrm{E}-01$ \\
\hline FABP4 & 32,935 & 34,143 & $-1,208$ & $2,608 \mathrm{E}-02$ \\
\hline EIF4G2 & 22,870 & 24,078 & $-1,208$ & $1,477 \mathrm{E}-01$ \\
\hline SDHC & 23,440 & 24,640 & $-1,200$ & $1,993 \mathrm{E}-01$ \\
\hline VAMP2 & 21,287 & 22,480 & $-1,193$ & $3,004 \mathrm{E}-01$ \\
\hline LIPE & 30,383 & 31,570 & $-1,188$ & $1,674 \mathrm{E}-02$ \\
\hline NUDT14 & 20,362 & 21,544 & $-1,183$ & $2,165 \mathrm{E}-01$ \\
\hline LDHB & 30,063 & 31,238 & $-1,175$ & $2,967 \mathrm{E}-02$ \\
\hline ELOVL5 & 23,850 & 25,008 & $-1,158$ & $3,533 \mathrm{E}-02$ \\
\hline ADH5 & 27,823 & 28,978 & $-1,155$ & $3,581 \mathrm{E}-02$ \\
\hline AGL & 21,200 & 22,353 & $-1,153$ & $3,662 \mathrm{E}-01$ \\
\hline CALU & 20,402 & 21,546 & $-1,143$ & $4,410 \mathrm{E}-01$ \\
\hline AGPAT3 & 23,693 & 24,803 & $-1,110$ & $1,558 \mathrm{E}-01$ \\
\hline ALDOA & 30,130 & 31,230 & $-1,100$ & $4,271 \mathrm{E}-02$ \\
\hline ECHS1 & 29,710 & 30,810 & $-1,100$ & $4,715 \mathrm{E}-02$ \\
\hline PYGL & 29,710 & 30,798 & $-1,088$ & $6,288 \mathrm{E}-02$ \\
\hline LMNA & 32,478 & 32,663 & $-1,085$ & $7,168 \mathrm{E}-02$ \\
\hline MTAP & 23,511 & 24,595 & $-1,084$ & $1,741 \mathrm{E}-01$ \\
\hline FITM2 & 23,398 & 24,478 & $-1,080$ & $5,798 \mathrm{E}-02$ \\
\hline PCBP2 & 25,328 & 25,410 & $-1,079$ & $2,997 \mathrm{E}-01$ \\
\hline STAT5A & 25,683 & 26,758 & $-1,075$ & $1,823 \mathrm{E}-01$ \\
\hline SHMT1 & 24,575 & 25,645 & $-1,070$ & $1,526 \mathrm{E}-01$ \\
\hline RRAS2 & 26,798 & 27,858 & $-1,060$ & $1,652 \mathrm{E}-02$ \\
\hline ENO1 & 31,025 & 32,075 & $-1,050$ & 7,524E-02 \\
\hline UGP2 & 30,373 & 31,420 & $-1,048$ & $5,928 \mathrm{E}-02$ \\
\hline
\end{tabular}




\begin{tabular}{|c|c|c|c|c|}
\hline COL4A3BP & 21,720 & 22,760 & $-1,040$ & $1,652 \mathrm{E}-01$ \\
\hline JAK1 & 20,344 & 21,375 & $-1,031$ & $1,251 \mathrm{E}-01$ \\
\hline SCD & 26,323 & 27,353 & $-1,030$ & $2,444 \mathrm{E}-01$ \\
\hline CAV1 & 27,958 & 27,965 & $-1,025$ & $6,888 \mathrm{E}-02$ \\
\hline ADH1B & 31,945 & 32,968 & $-1,022$ & $6,785 \mathrm{E}-02$ \\
\hline GMPPB & 20,315 & 21,326 & $-1,011$ & $4,475 \mathrm{E}-01$ \\
\hline AKT2 & 23,548 & 24,558 & $-1,010$ & $5,896 \mathrm{E}-02$ \\
\hline MYH7 & 22,304 & 23,298 & $-0,994$ & $6,288 \mathrm{E}-01$ \\
\hline PEA15 & 24,450 & 25,443 & $-0,992$ & $5,581 \mathrm{E}-02$ \\
\hline STAT5B & 22,183 & 23,173 & $-0,989$ & $2,915 \mathrm{E}-01$ \\
\hline ACACA & 24,598 & 25,578 & $-0,980$ & $4,458 \mathrm{E}-01$ \\
\hline MAPK3 & 24,765 & 25,743 & $-0,978$ & $1,467 \mathrm{E}-01$ \\
\hline PTPN11 & 24,473 & 25,448 & $-0,975$ & $1,107 \mathrm{E}-01$ \\
\hline TPT1 & 25,693 & 26,668 & $-0,975$ & $1,353 \mathrm{E}-01$ \\
\hline GRHPR & 26,143 & 27,115 & $-0,973$ & 7,497E-02 \\
\hline ECI2 & 23,563 & 24,523 & $-0,960$ & $6,278 \mathrm{E}-02$ \\
\hline RGN & 21,100 & 22,058 & $-0,958$ & $2,620 \mathrm{E}-01$ \\
\hline ALDH2 & 31,980 & 32,935 & $-0,955$ & $8,121 \mathrm{E}-02$ \\
\hline PPP1CC & 21,130 & 22,080 & $-0,950$ & $2,207 \mathrm{E}-01$ \\
\hline MECR & 23,565 & 24,510 & $-0,945$ & $9,104 \mathrm{E}-02$ \\
\hline SLC25A10 & 24,358 & 25,300 & $-0,942$ & $8,690 \mathrm{E}-02$ \\
\hline OXCT1 & 28,070 & 29,008 & $-0,938$ & $6,051 \mathrm{E}-02$ \\
\hline LNPEP & 26,973 & 27,903 & $-0,930$ & $1,339 \mathrm{E}-01$ \\
\hline SOD2 & 29,673 & 30,603 & $-0,930$ & $8,928 \mathrm{E}-02$ \\
\hline G0S2 & 21,776 & 22,705 & $-0,929$ & $2,520 \mathrm{E}-01$ \\
\hline HAGH & 24,130 & 25,048 & $-0,918$ & $5,911 \mathrm{E}-02$ \\
\hline MUT & 25,018 & 25,935 & $-0,917$ & $1,801 \mathrm{E}-01$ \\
\hline ANXA2 & 34,183 & 35,095 & $-0,912$ & $2,814 \mathrm{E}-02$ \\
\hline CRK & 25,943 & 26,845 & $-0,903$ & $1,054 \mathrm{E}-01$ \\
\hline RAB5A & 25,315 & 26,213 & $-0,897$ & $4,840 \mathrm{E}-02$ \\
\hline $\mathrm{ACO} 1$ & 29,453 & 30,335 & $-0,883$ & $1,360 \mathrm{E}-01$ \\
\hline ACAA1 & 25,528 & 26,403 & $-0,875$ & 7,343E-02 \\
\hline IDH3A & 26,998 & 27,873 & $-0,875$ & $7,145 \mathrm{E}-02$ \\
\hline GAPDH & 30,563 & 31,435 & $-0,873$ & $5,790 \mathrm{E}-02$ \\
\hline CAMK1 & 22,318 & 23,185 & $-0,868$ & $1,827 \mathrm{E}-01$ \\
\hline RHOA & 27,368 & 28,233 & $-0,865$ & $6,350 \mathrm{E}-02$ \\
\hline EIF4G1 & 24,173 & 25,035 & $-0,863$ & $2,585 \mathrm{E}-01$ \\
\hline EIF2S3 & 25,833 & 26,693 & $-0,860$ & $1,664 \mathrm{E}-01$ \\
\hline THRSP & 20,503 & 21,363 & $-0,859$ & $1,567 \mathrm{E}-01$ \\
\hline EIF4E & 22,545 & 23,403 & $-0,858$ & $3,308 \mathrm{E}-01$ \\
\hline NFKB1 & 21,205 & 22,063 & $-0,858$ & $2,634 \mathrm{E}-01$ \\
\hline PPIA & 30,053 & 30,910 & $-0,857$ & $1,421 \mathrm{E}-01$ \\
\hline FASN & 30,600 & 31,458 & $-0,857$ & $2,883 \mathrm{E}-01$ \\
\hline HADHB & 30,380 & 31,233 & $-0,852$ & $5,646 \mathrm{E}-02$ \\
\hline PECR & 27,355 & 28,208 & $-0,852$ & $6,796 \mathrm{E}-02$ \\
\hline
\end{tabular}




\begin{tabular}{|c|c|c|c|c|}
\hline MIF & 23,883 & 24,728 & $-0,845$ & $2,918 \mathrm{E}-01$ \\
\hline TSPO & 27,083 & 27,928 & $-0,845$ & $1,132 \mathrm{E}-01$ \\
\hline ACADS & 28,128 & 28,960 & $-0,833$ & $7,945 \mathrm{E}-02$ \\
\hline GPI & 25,183 & 26,010 & $-0,827$ & $1,741 \mathrm{E}-01$ \\
\hline ALDH1B1 & 25,643 & 26,465 & $-0,823$ & $1,673 \mathrm{E}-01$ \\
\hline RRAS & 29,753 & 30,575 & $-0,823$ & 7,384E-02 \\
\hline PPP2CA & 24,073 & 24,893 & $-0,820$ & $2,076 \mathrm{E}-01$ \\
\hline ACOT1 & 29,290 & 30,103 & $-0,813$ & $1,188 \mathrm{E}-01$ \\
\hline PGD & 29,210 & 30,023 & $-0,813$ & $1,356 \mathrm{E}-01$ \\
\hline PGK1 & 29,808 & 30,615 & $-0,808$ & $1,586 \mathrm{E}-01$ \\
\hline $\mathrm{CS}$ & 30,343 & 31,145 & $-0,802$ & 1,349E-01 \\
\hline MMAA & 20,523 & 21,308 & $-0,785$ & $1,558 \mathrm{E}-01$ \\
\hline ALDH3A2 & 29,280 & 30,060 & $-0,780$ & $6,119 \mathrm{E}-02$ \\
\hline KRAS & 25,825 & 26,600 & $-0,775$ & $1,303 \mathrm{E}-01$ \\
\hline CALM3 & 28,003 & 28,773 & $-0,770$ & $1,549 \mathrm{E}-01$ \\
\hline EIF2S1 & 25,945 & 26,710 & $-0,765$ & $1,644 \mathrm{E}-01$ \\
\hline LDHD & 22,758 & 23,523 & $-0,765$ & $3,230 \mathrm{E}-01$ \\
\hline PCCA & 26,190 & 26,955 & $-0,765$ & $3,906 \mathrm{E}-01$ \\
\hline GPD1L & 22,261 & 23,021 & $-0,760$ & $6,414 \mathrm{E}-01$ \\
\hline EIF4A2 & 25,080 & 25,833 & $-0,752$ & $3,458 \mathrm{E}-01$ \\
\hline GPX4 & 27,275 & 28,020 & $-0,745$ & $1,683 \mathrm{E}-01$ \\
\hline PPP1CB & 25,200 & 25,943 & $-0,742$ & $1,579 \mathrm{E}-01$ \\
\hline PDHX & 25,648 & 26,388 & $-0,740$ & $1,683 \mathrm{E}-01$ \\
\hline LMF1 & 21,719 & 22,458 & $-0,738$ & $4,513 \mathrm{E}-01$ \\
\hline PPP2R2A & 24,848 & 25,585 & $-0,738$ & $3,263 \mathrm{E}-01$ \\
\hline SUCLG1 & 27,448 & 28,178 & $-0,730$ & $1,321 \mathrm{E}-01$ \\
\hline VAPA & 26,855 & 27,568 & $-0,712$ & 9,879E-02 \\
\hline $\mathrm{ABCC} 1$ & 19,646 & 20,353 & $-0,707$ & $9,581 \mathrm{E}-02$ \\
\hline FH & 28,843 & 29,548 & $-0,705$ & $9,951 \mathrm{E}-02$ \\
\hline PRKAG1 & 23,095 & 23,800 & $-0,705$ & $4,227 \mathrm{E}-01$ \\
\hline CAT & 31,095 & 31,798 & $-0,703$ & $1,287 \mathrm{E}-01$ \\
\hline SEC24A & 19,860 & 20,562 & $-0,701$ & $2,690 \mathrm{E}-01$ \\
\hline LPIN1 & 21,059 & 21,758 & $-0,699$ & $2,660 \mathrm{E}-01$ \\
\hline NCL & 27,858 & 28,545 & $-0,688$ & $2,326 \mathrm{E}-01$ \\
\hline CALU & 28,695 & 29,378 & $-0,682$ & $1,644 \mathrm{E}-01$ \\
\hline PGLS & 25,130 & 25,805 & $-0,675$ & $3,468 \mathrm{E}-01$ \\
\hline GLB1 & 21,619 & 22,285 & $-0,666$ & $3,993 \mathrm{E}-01$ \\
\hline PYGM & 21,294 & 21,960 & $-0,666$ & $3,060 \mathrm{E}-01$ \\
\hline TALDO1 & 28,683 & 29,348 & $-0,665$ & $1,908 \mathrm{E}-01$ \\
\hline ACAA2 & 30,213 & 30,878 & $-0,665$ & 1,494E-01 \\
\hline AKR1B1 & 24,163 & 24,825 & $-0,662$ & $6,971 \mathrm{E}-01$ \\
\hline BCAT2 & 24,810 & 25,470 & $-0,660$ & $2,511 \mathrm{E}-01$ \\
\hline CYCS & 26,935 & 27,588 & $-0,652$ & $1,608 \mathrm{E}-01$ \\
\hline HMGCL & 25,485 & 26,135 & $-0,650$ & $2,553 \mathrm{E}-01$ \\
\hline ACOT13 & 26,553 & 27,200 & $-0,648$ & $1,992 \mathrm{E}-01$ \\
\hline
\end{tabular}




\begin{tabular}{|c|c|c|c|c|}
\hline CLIC4 & 24,415 & 25,060 & $-0,645$ & $5,769 \mathrm{E}-01$ \\
\hline CBR1 & 26,430 & 27,073 & $-0,642$ & $2,177 \mathrm{E}-01$ \\
\hline SUCLG2 & 28,205 & 28,843 & $-0,637$ & $1,526 \mathrm{E}-01$ \\
\hline C1QBP & 26,195 & 26,825 & $-0,630$ & $1,668 \mathrm{E}-01$ \\
\hline PRKAR2B & 28,915 & 29,545 & $-0,630$ & $2,234 \mathrm{E}-01$ \\
\hline AP2A1 & 25,335 & 25,958 & $-0,622$ & $6,271 \mathrm{E}-01$ \\
\hline DLST & 29,028 & 29,648 & $-0,620$ & $1,610 \mathrm{E}-01$ \\
\hline PCCB & 26,420 & 27,030 & $-0,610$ & $3,193 \mathrm{E}-01$ \\
\hline ILK & 28,618 & 29,225 & $-0,608$ & $2,996 \mathrm{E}-01$ \\
\hline EGFR & 24,615 & 25,223 & $-0,608$ & $2,175 \mathrm{E}-01$ \\
\hline AKT1 & 20,992 & 21,595 & $-0,603$ & 4,504E-01 \\
\hline MDH2 & 29,795 & 30,395 & $-0,600$ & $1,701 \mathrm{E}-01$ \\
\hline DERA & 22,394 & 22,983 & $-0,589$ & $5,086 \mathrm{E}-01$ \\
\hline GFPT1 & 23,475 & 24,060 & $-0,585$ & $5,159 \mathrm{E}-01$ \\
\hline NANS & 22,890 & 23,468 & $-0,578$ & $5,148 \mathrm{E}-01$ \\
\hline GLTP & 22,315 & 22,888 & $-0,573$ & $2,293 \mathrm{E}-01$ \\
\hline CTBP1 & 22,645 & 23,215 & $-0,570$ & 4,174E-01 \\
\hline АТР2B4 & 28,193 & 28,760 & $-0,568$ & $3,037 \mathrm{E}-01$ \\
\hline FKBP4 & 21,975 & 22,535 & $-0,560$ & $6,602 \mathrm{E}-01$ \\
\hline EIF2AK2 & 21,151 & 21,710 & $-0,559$ & $3,927 \mathrm{E}-01$ \\
\hline TNFAIP8L2 & 20,415 & 20,968 & $-0,553$ & $3,841 \mathrm{E}-01$ \\
\hline DLD & 29,223 & 29,775 & $-0,553$ & $2,426 \mathrm{E}-01$ \\
\hline MAPK14 & 21,572 & 22,123 & $-0,551$ & 4,852E-01 \\
\hline PDHB & 28,255 & 28,798 & $-0,543$ & $2,621 \mathrm{E}-01$ \\
\hline RAB7A & 29,295 & 29,838 & $-0,543$ & 1,909E-01 \\
\hline ABHD5 & 27,765 & 28,308 & $-0,543$ & $2,076 \mathrm{E}-01$ \\
\hline SUCLA2 & 27,880 & 28,408 & $-0,527$ & $2,437 \mathrm{E}-01$ \\
\hline RAB14 & 29,135 & 29,658 & $-0,523$ & $3,036 \mathrm{E}-01$ \\
\hline CD36 & 33,253 & 33,753 & $-0,500$ & $3,204 \mathrm{E}-01$ \\
\hline CIDEC & 21,030 & 21,530 & $-0,500$ & $3,684 \mathrm{E}-01$ \\
\hline IDH3G & 25,705 & 26,203 & $-0,498$ & $2,559 \mathrm{E}-01$ \\
\hline AGPAT2 & 26,430 & 26,928 & $-0,497$ & $3,141 \mathrm{E}-01$ \\
\hline RAP1B & 25,225 & 25,718 & $-0,493$ & $2,454 \mathrm{E}-01$ \\
\hline GMPPA & 22,403 & 22,895 & $-0,492$ & $4,502 \mathrm{E}-01$ \\
\hline $\mathrm{ACACB}$ & 27,430 & 27,920 & $-0,490$ & 5,297E-01 \\
\hline PGAM1 & 28,978 & 29,465 & $-0,488$ & $3,592 \mathrm{E}-01$ \\
\hline GNA12 & 21,925 & 22,413 & $-0,487$ & $3,618 \mathrm{E}-01$ \\
\hline BCL2 & 24,588 & 25,068 & $-0,480$ & $3,976 \mathrm{E}-01$ \\
\hline GLUD1 & 29,300 & 29,780 & $-0,480$ & $2,506 \mathrm{E}-01$ \\
\hline РPР3CB & 23,345 & 23,813 & $-0,467$ & 4,656E- 01 \\
\hline ALDH9A1 & 28,690 & 29,150 & $-0,460$ & 4,400E-01 \\
\hline LTA4H & 24,930 & 25,388 & $-0,458$ & $6,721 \mathrm{E}-01$ \\
\hline NSDHL & 24,625 & 25,083 & $-0,457$ & $3,236 \mathrm{E}-01$ \\
\hline MPC2 & 26,690 & 27,145 & $-0,455$ & $3,426 \mathrm{E}-01$ \\
\hline CSNK2A2 & 24,240 & 24,693 & $-0,453$ & $3,498 \mathrm{E}-01$ \\
\hline
\end{tabular}




\begin{tabular}{|c|c|c|c|c|}
\hline PAFAH1B1 & 26,225 & 26,668 & $-0,442$ & $3,707 \mathrm{E}-01$ \\
\hline ALG5 & 24,298 & 24,740 & $-0,442$ & 2,392E-01 \\
\hline RPS6 & 24,880 & 25,318 & $-0,438$ & $2,872 \mathrm{E}-01$ \\
\hline PAFAH1B2 & 24,738 & 25,165 & $-0,427$ & 4,904E-01 \\
\hline PPID & 20,817 & 21,243 & $-0,425$ & $3,819 \mathrm{E}-01$ \\
\hline SORT1 & 25,568 & 25,988 & $-0,420$ & $3,812 \mathrm{E}-01$ \\
\hline RAP1A & 29,748 & 30,163 & $-0,415$ & $3,081 \mathrm{E}-01$ \\
\hline CTSD & 29,870 & 30,270 & $-0,400$ & $3,224 \mathrm{E}-01$ \\
\hline SLC27A4 & 21,114 & 21,505 & $-0,391$ & $5,333 \mathrm{E}-01$ \\
\hline RHEB & 24,123 & 24,513 & $-0,390$ & $3,684 \mathrm{E}-01$ \\
\hline LONP1 & 26,935 & 27,320 & $-0,385$ & 4,389E-01 \\
\hline CTSA & 23,572 & 23,955 & $-0,383$ & $6,431 \mathrm{E}-01$ \\
\hline ACADL & 23,235 & 23,618 & $-0,383$ & $8,034 \mathrm{E}-01$ \\
\hline ACOX 2 & 21,435 & 21,815 & $-0,380$ & $5,367 \mathrm{E}-01$ \\
\hline HSD11B1 & 23,778 & 24,155 & $-0,378$ & $5,095 \mathrm{E}-01$ \\
\hline OGDH & 28,125 & 28,498 & $-0,372$ & $6,288 \mathrm{E}-01$ \\
\hline TPI1 & 29,525 & 29,893 & $-0,368$ & $5,097 \mathrm{E}-01$ \\
\hline TXNRD1 & 22,601 & 22,968 & $-0,367$ & 7,535E-01 \\
\hline SRC & 20,872 & 21,230 & $-0,358$ & $6,435 \mathrm{E}-01$ \\
\hline RHOT2 & 21,113 & 21,462 & $-0,349$ & $6,649 \mathrm{E}-01$ \\
\hline HADHA & 30,450 & 30,795 & $-0,345$ & $5,498 \mathrm{E}-01$ \\
\hline PCYT1A & 25,275 & 25,620 & $-0,345$ & $4,611 \mathrm{E}-01$ \\
\hline AHCYL1 & 24,998 & 25,338 & $-0,340$ & $5,631 \mathrm{E}-01$ \\
\hline HDLBP & 23,980 & 24,320 & $-0,340$ & $6,089 \mathrm{E}-01$ \\
\hline NDUFAB1 & 25,295 & 25,635 & $-0,340$ & 5,419E-01 \\
\hline LRPAP1 & 27,390 & 27,720 & $-0,330$ & $5,653 \mathrm{E}-01$ \\
\hline ORMDL2 & 24,585 & 24,915 & $-0,330$ & $4,546 \mathrm{E}-01$ \\
\hline ACSL1 & 31,823 & 32,150 & $-0,327$ & $5,661 \mathrm{E}-01$ \\
\hline PPP2R5A & 24,455 & 24,780 & $-0,325$ & $4,577 \mathrm{E}-01$ \\
\hline PLA2G4A & 22,945 & 23,265 & $-0,320$ & $7,038 \mathrm{E}-01$ \\
\hline ARCN1 & 25,655 & 25,973 & $-0,317$ & $5,261 \mathrm{E}-01$ \\
\hline GPX1 & 27,760 & 28,073 & $-0,313$ & $6,313 \mathrm{E}-01$ \\
\hline PPP2R1A & 26,995 & 27,305 & $-0,310$ & $6,006 \mathrm{E}-01$ \\
\hline ACADVL & 30,198 & 30,503 & $-0,305$ & $4,925 \mathrm{E}-01$ \\
\hline GLO1 & 25,355 & 25,660 & $-0,305$ & $6,636 \mathrm{E}-01$ \\
\hline AGK & 23,355 & 23,658 & $-0,302$ & $6,816 \mathrm{E}-01$ \\
\hline PDHA1 & 28,103 & 28,393 & $-0,290$ & 5,719E-01 \\
\hline SLC25A1 & 28,795 & 29,083 & $-0,288$ & $5,751 \mathrm{E}-01$ \\
\hline ACOT9 & 26,268 & 26,555 & $-0,287$ & $5,447 \mathrm{E}-01$ \\
\hline RAC1 & 21,598 & 21,876 & $-0,278$ & $8,000 \mathrm{E}-01$ \\
\hline ACSF2 & 26,685 & 26,963 & $-0,278$ & $7,720 \mathrm{E}-01$ \\
\hline ARF1 & 28,873 & 29,143 & $-0,270$ & $6,100 \mathrm{E}-01$ \\
\hline ACOX1 & 26,630 & 26,893 & $-0,262$ & 4,995E-01 \\
\hline MBNL1 & 21,482 & 21,740 & $-0,258$ & $5,905 \mathrm{E}-01$ \\
\hline ACADM & 28,645 & 28,903 & $-0,258$ & $6,378 \mathrm{E}-01$ \\
\hline
\end{tabular}




\begin{tabular}{|c|c|c|c|c|}
\hline CAB39 & 24,205 & 24,460 & $-0,255$ & $6,102 \mathrm{E}-01$ \\
\hline DMGDH & 21,395 & 21,650 & $-0,255$ & $6,445 \mathrm{E}-01$ \\
\hline PPP2R5D & 22,313 & 22,563 & $-0,250$ & $6,735 \mathrm{E}-01$ \\
\hline PRDX1 & 29,515 & 29,765 & $-0,250$ & $6,517 \mathrm{E}-01$ \\
\hline ECI1 & 26,585 & 26,830 & $-0,245$ & $6,288 \mathrm{E}-01$ \\
\hline PRDX2 & 29,950 & 30,183 & $-0,232$ & $6,284 \mathrm{E}-01$ \\
\hline ALDH7A1 & 27,715 & 27,943 & $-0,228$ & $5,909 \mathrm{E}-01$ \\
\hline PRKAR2A & 27,025 & 27,253 & $-0,228$ & $6,446 \mathrm{E}-01$ \\
\hline TXNRD2 & 22,968 & 23,195 & $-0,228$ & $7,202 \mathrm{E}-01$ \\
\hline CBR4 & 22,803 & 23,030 & $-0,227$ & $6,718 \mathrm{E}-01$ \\
\hline MAP2K1 & 26,143 & 26,365 & $-0,222$ & $6,870 \mathrm{E}-01$ \\
\hline PRPS1 & 23,850 & 24,070 & $-0,220$ & $6,957 \mathrm{E}-01$ \\
\hline FABP5 & 28,043 & 28,260 & $-0,217$ & $7,938 \mathrm{E}-01$ \\
\hline PRKACB & 25,698 & 25,913 & $-0,215$ & $6,845 \mathrm{E}-01$ \\
\hline PTGES2 & 26,315 & 26,530 & $-0,215$ & $6,258 \mathrm{E}-01$ \\
\hline SIRT3 & 22,273 & 22,485 & $-0,212$ & $6,180 \mathrm{E}-01$ \\
\hline RPS27A & 30,510 & 30,723 & $-0,212$ & $6,403 \mathrm{E}-01$ \\
\hline CPNE1 & 22,830 & 23,035 & $-0,205$ & $8,130 \mathrm{E}-01$ \\
\hline EIF4A1 & 28,038 & 28,240 & $-0,202$ & $7,332 \mathrm{E}-01$ \\
\hline ACOX3 & 20,660 & 20,855 & $-0,195$ & $7,095 \mathrm{E}-01$ \\
\hline AKR1A1 & 26,888 & 27,080 & $-0,193$ & $7,680 \mathrm{E}-01$ \\
\hline OPA1 & 26,870 & 27,063 & $-0,193$ & $7,149 \mathrm{E}-01$ \\
\hline SDHA & 28,620 & 28,808 & $-0,188$ & $7,559 \mathrm{E}-01$ \\
\hline EHHADH & 25,390 & 25,578 & $-0,188$ & $7,765 \mathrm{E}-01$ \\
\hline LMNA & 26,265 & 27,350 & $-0,185$ & $6,737 \mathrm{E}-01$ \\
\hline HSD17B8 & 23,960 & 24,143 & $-0,183$ & $7,032 \mathrm{E}-01$ \\
\hline SUMF1 & 22,393 & 22,573 & $-0,180$ & $7,087 \mathrm{E}-01$ \\
\hline SLC2A4 & 24,963 & 25,143 & $-0,180$ & $6,969 \mathrm{E}-01$ \\
\hline EIF2B4 & 20,996 & 21,172 & $-0,176$ & $7,822 \mathrm{E}-01$ \\
\hline MAPK10 & 20,077 & 20,248 & $-0,170$ & $8,462 \mathrm{E}-01$ \\
\hline SDHB & 27,208 & 27,365 & $-0,157$ & $7,565 \mathrm{E}-01$ \\
\hline COPZ1 & 23,603 & 23,753 & $-0,150$ & 7,910E-01 \\
\hline STAT6 & 22,450 & 22,600 & $-0,150$ & $8,634 \mathrm{E}-01$ \\
\hline DLAT & 28,483 & 28,630 & $-0,148$ & 7,965E-01 \\
\hline HSD17B4 & 28,750 & 28,888 & $-0,137$ & $7,051 \mathrm{E}-01$ \\
\hline PKM & 29,508 & 29,640 & $-0,133$ & $8,448 \mathrm{E}-01$ \\
\hline ITGB1 & 31,088 & 31,208 & $-0,120$ & $8,006 \mathrm{E}-01$ \\
\hline PGRMC1 & 28,945 & 29,060 & $-0,115$ & $8,409 \mathrm{E}-01$ \\
\hline PTPN1 & 22,534 & 22,648 & $-0,113$ & $7,828 \mathrm{E}-01$ \\
\hline $\mathrm{ACO} 2$ & 29,810 & 29,920 & $-0,110$ & $8,446 \mathrm{E}-01$ \\
\hline KPNB1 & 26,980 & 27,090 & $-0,110$ & $8,399 \mathrm{E}-01$ \\
\hline MFN2 & 23,533 & 23,643 & $-0,110$ & $8,982 \mathrm{E}-01$ \\
\hline PTGES3 & 23,418 & 23,528 & $-0,110$ & $8,705 \mathrm{E}-01$ \\
\hline ABHD6 & 20,067 & 20,166 & $-0,099$ & $8,263 \mathrm{E}-01$ \\
\hline ASAH1 & 28,788 & 28,880 & $-0,093$ & $8,383 \mathrm{E}-01$ \\
\hline
\end{tabular}




\begin{tabular}{|c|c|c|c|c|}
\hline TM7SF2 & 24,763 & 24,855 & $-0,093$ & $8,803 \mathrm{E}-01$ \\
\hline FDPS & 24,825 & 24,913 & $-0,087$ & $9,123 \mathrm{E}-01$ \\
\hline PCBP2 & 20,363 & 21,441 & $-0,082$ & $8,716 \mathrm{E}-01$ \\
\hline TBC1D4 & 19,569 & 19,650 & $-0,081$ & $9,150 \mathrm{E}-01$ \\
\hline PIK3C3 & 20,449 & 20,529 & $-0,080$ & $9,225 \mathrm{E}-01$ \\
\hline ACSS3 & 26,318 & 26,395 & $-0,078$ & $8,845 \mathrm{E}-01$ \\
\hline INPP5K & 22,288 & 22,363 & $-0,075$ & $8,497 \mathrm{E}-01$ \\
\hline SEC23A & 25,588 & 25,663 & $-0,075$ & $9,066 \mathrm{E}-01$ \\
\hline CES1 & 33,438 & 33,500 & $-0,062$ & $9,284 \mathrm{E}-01$ \\
\hline TXN & 26,313 & 26,373 & $-0,060$ & $9,126 \mathrm{E}-01$ \\
\hline $\mathrm{SCP} 2$ & 27,105 & 27,165 & $-0,060$ & $8,954 \mathrm{E}-01$ \\
\hline PMVK & 21,574 & 21,634 & $-0,059$ & $9,446 \mathrm{E}-01$ \\
\hline GNAI1 & 27,903 & 27,953 & $-0,050$ & $9,270 \mathrm{E}-01$ \\
\hline VDAC1 & 30,060 & 30,105 & $-0,045$ & $9,123 \mathrm{E}-01$ \\
\hline STAT3 & 25,490 & 25,535 & $-0,045$ & $9,584 \mathrm{E}-01$ \\
\hline ADIPOQ & 26,768 & 26,805 & $-0,038$ & $9,395 \mathrm{E}-01$ \\
\hline ROCK1 & 21,362 & 21,395 & $-0,033$ & $9,768 \mathrm{E}-01$ \\
\hline DGAT1 & 25,108 & 25,140 & $-0,032$ & $9,518 \mathrm{E}-01$ \\
\hline MPC1 & 24,775 & 24,798 & $-0,023$ & $9,599 \mathrm{E}-01$ \\
\hline S100A1 & 21,333 & 21,353 & $-0,021$ & $9,871 \mathrm{E}-01$ \\
\hline PON2 & 27,218 & 27,233 & $-0,015$ & $9,747 \mathrm{E}-01$ \\
\hline CAV1 & 33,368 & 34,393 & $-0,008$ & $9,938 \mathrm{E}-01$ \\
\hline TPM1 & 23,975 & 23,980 & $-0,005$ & $9,921 \mathrm{E}-01$ \\
\hline NCOA2 & 23,270 & 23,270 & 0,000 & $1,000 \mathrm{E}+00$ \\
\hline AP2A2 & 25,518 & 25,515 & 0,003 & 9,979E-01 \\
\hline SLC25A11 & 28,483 & 28,480 & 0,003 & $9,954 \mathrm{E}-01$ \\
\hline VAC14 & 23,808 & 23,798 & 0,010 & $9,874 \mathrm{E}-01$ \\
\hline $\mathrm{PC}$ & 30,178 & 30,168 & 0,010 & $9,847 \mathrm{E}-01$ \\
\hline PLBD1 & 22,825 & 22,810 & 0,015 & $9,824 \mathrm{E}-01$ \\
\hline COPG1 & 24,720 & 24,700 & 0,020 & $9,788 \mathrm{E}-01$ \\
\hline AP2B1 & 26,913 & 26,868 & 0,045 & 9,329E-01 \\
\hline RUFY1 & 21,838 & 21,780 & 0,058 & $9,355 \mathrm{E}-01$ \\
\hline PTPMT1 & 22,998 & 22,938 & 0,060 & $9,036 \mathrm{E}-01$ \\
\hline IL6ST & 21,391 & 21,321 & 0,070 & $9,235 \mathrm{E}-01$ \\
\hline LDLRAP1 & 19,544 & 19,470 & 0,074 & $8,895 \mathrm{E}-01$ \\
\hline СРT2 & 26,068 & 25,993 & 0,075 & $8,980 \mathrm{E}-01$ \\
\hline SLC25A5 & 28,065 & 27,973 & 0,092 & $8,147 \mathrm{E}-01$ \\
\hline MAPK1 & 26,530 & 26,438 & 0,093 & $8,775 \mathrm{E}-01$ \\
\hline PNPLA2 & 25,950 & 25,853 & 0,097 & $8,294 \mathrm{E}-01$ \\
\hline RAN & 27,415 & 27,315 & 0,100 & $8,537 \mathrm{E}-01$ \\
\hline G6PD & 23,448 & 24,695 & 0,103 & $8,594 \mathrm{E}-01$ \\
\hline HSPA5 & 31,928 & 31,818 & 0,110 & $8,099 \mathrm{E}-01$ \\
\hline PNPLA8 & 20,399 & 20,288 & 0,111 & $8,170 \mathrm{E}-01$ \\
\hline PCK1 & 25,128 & 25,015 & 0,113 & 8,337E-01 \\
\hline MCU & 24,275 & 24,160 & 0,115 & $8,109 \mathrm{E}-01$ \\
\hline
\end{tabular}




\begin{tabular}{|c|c|c|c|c|}
\hline IGF2R & 22,825 & 22,703 & 0,123 & $7,513 \mathrm{E}-01$ \\
\hline PGM3 & 24,003 & 23,873 & 0,130 & $7,376 \mathrm{E}-01$ \\
\hline NPC2 & 22,299 & 22,165 & 0,134 & $8,323 \mathrm{E}-01$ \\
\hline COX4I1 & 30,003 & 29,858 & 0,145 & $7,614 \mathrm{E}-01$ \\
\hline VDAC2 & 29,335 & 29,183 & 0,153 & $7,197 \mathrm{E}-01$ \\
\hline SIRT5 & 21,632 & 21,463 & 0,169 & $6,768 \mathrm{E}-01$ \\
\hline ESYT2 & 28,400 & 28,228 & 0,172 & $7,127 \mathrm{E}-01$ \\
\hline HSD17B12 & 29,238 & 29,063 & 0,175 & $6,932 \mathrm{E}-01$ \\
\hline WFS1 & 25,410 & 25,230 & 0,180 & $7,388 \mathrm{E}-01$ \\
\hline ANXA7 & 27,615 & 27,425 & 0,190 & $6,878 \mathrm{E}-01$ \\
\hline ACAT2 & 23,025 & 22,827 & 0,198 & $8,506 \mathrm{E}-01$ \\
\hline PRKACA & 29,903 & 29,703 & 0,200 & $6,638 \mathrm{E}-01$ \\
\hline DHCR7 & 24,095 & 23,890 & 0,205 & $6,676 \mathrm{E}-01$ \\
\hline $\mathrm{CDC} 42$ & 27,693 & 27,483 & 0,210 & $5,829 \mathrm{E}-01$ \\
\hline RHOQ & 22,440 & 22,228 & 0,213 & $6,985 \mathrm{E}-01$ \\
\hline P4HB & 32,263 & 32,050 & 0,213 & $6,262 \mathrm{E}-01$ \\
\hline CARM1 & 21,909 & 21,678 & 0,232 & $7,195 \mathrm{E}-01$ \\
\hline YAP1 & 23,905 & 23,663 & 0,242 & $6,723 \mathrm{E}-01$ \\
\hline H6PD & 27,663 & 27,420 & 0,243 & $5,989 \mathrm{E}-01$ \\
\hline SLC9A3R2 & 22,978 & 22,733 & 0,245 & $5,944 \mathrm{E}-01$ \\
\hline PRKAA1 & 23,493 & 23,245 & 0,248 & $6,717 \mathrm{E}-01$ \\
\hline PHKB & 20,700 & 20,450 & 0,249 & $7,253 \mathrm{E}-01$ \\
\hline LPGAT1 & 25,248 & 24,983 & 0,265 & $6,057 \mathrm{E}-01$ \\
\hline CPNE3 & 26,935 & 26,668 & 0,268 & $5,423 \mathrm{E}-01$ \\
\hline UGP2 & 22,192 & 21,924 & 0,268 & $8,071 \mathrm{E}-01$ \\
\hline IDH1 & 31,438 & 31,165 & 0,272 & $6,725 \mathrm{E}-01$ \\
\hline HK1 & 26,990 & 26,715 & 0,275 & $5,704 \mathrm{E}-01$ \\
\hline LEP & 23,165 & 22,888 & 0,277 & $8,457 \mathrm{E}-01$ \\
\hline PRKAR1A & 24,745 & 24,465 & 0,280 & $5,971 \mathrm{E}-01$ \\
\hline COPB2 & 25,823 & 25,540 & 0,282 & $7,023 \mathrm{E}-01$ \\
\hline OSBP & 23,355 & 23,068 & 0,287 & $6,015 \mathrm{E}-01$ \\
\hline RAC3 & 22,150 & 21,858 & 0,292 & 7,934E-01 \\
\hline EEF2 & 28,585 & 28,290 & 0,295 & $5,880 \mathrm{E}-01$ \\
\hline CSNK2B & 24,240 & 23,943 & 0,297 & $4,811 \mathrm{E}-01$ \\
\hline BID & 20,617 & 20,305 & 0,312 & 4,774E-01 \\
\hline RAC1 & 28,920 & 28,608 & 0,313 & 4,289E-01 \\
\hline PANK4 & 21,568 & 21,250 & 0,318 & $6,192 \mathrm{E}-01$ \\
\hline ACSF3 & 22,558 & 22,238 & 0,320 & $5,492 \mathrm{E}-01$ \\
\hline SLC27A1 & 25,828 & 25,503 & 0,325 & $6,558 \mathrm{E}-01$ \\
\hline ACTC1 & 30,865 & 30,528 & 0,337 & $5,789 \mathrm{E}-01$ \\
\hline PFKL & 27,468 & 27,128 & 0,340 & $5,191 \mathrm{E}-01$ \\
\hline ROCK2 & 21,610 & 21,270 & 0,340 & $6,863 \mathrm{E}-01$ \\
\hline SUMF2 & 26,235 & 25,885 & 0,350 & 5,431E-01 \\
\hline GNPDA1 & 24,165 & 23,800 & 0,365 & 7,674E-01 \\
\hline GAA & 24,515 & 24,145 & 0,370 & $5,027 \mathrm{E}-01$ \\
\hline
\end{tabular}




\begin{tabular}{|c|c|c|c|c|}
\hline CDIPT & 25,733 & 25,360 & 0,372 & $3,732 \mathrm{E}-01$ \\
\hline CDS2 & 24,993 & 24,613 & 0,380 & $4,958 \mathrm{E}-01$ \\
\hline DEGS1 & 22,763 & 22,375 & 0,387 & $2,971 \mathrm{E}-01$ \\
\hline SERINC1 & 23,023 & 22,623 & 0,400 & $4,176 \mathrm{E}-01$ \\
\hline TRADD & 21,042 & 20,632 & 0,409 & $6,571 \mathrm{E}-01$ \\
\hline EIF2B1 & 24,098 & 23,685 & 0,412 & $5,169 \mathrm{E}-01$ \\
\hline ALG12 & 21,448 & 21,036 & 0,413 & $6,181 \mathrm{E}-01$ \\
\hline MLYCD & 24,013 & 23,595 & 0,417 & $5,866 \mathrm{E}-01$ \\
\hline APOA1 & 30,900 & 30,480 & 0,420 & $3,697 \mathrm{E}-01$ \\
\hline CERS4 & 20,815 & 20,395 & 0,420 & $2,896 \mathrm{E}-01$ \\
\hline ATP1B3 & 26,463 & 26,040 & 0,422 & $3,216 \mathrm{E}-01$ \\
\hline ZMPSTE24 & 25,538 & 25,110 & 0,428 & $3,707 \mathrm{E}-01$ \\
\hline ELOVL1 & 22,203 & 21,750 & 0,453 & $2,871 \mathrm{E}-01$ \\
\hline CSNK2A1 & 27,303 & 26,845 & 0,458 & $2,973 \mathrm{E}-01$ \\
\hline TPP2 & 20,866 & 20,403 & 0,463 & $5,714 \mathrm{E}-01$ \\
\hline GNAI3 & 26,690 & 26,225 & 0,465 & $3,420 \mathrm{E}-01$ \\
\hline AP2M1 & 27,298 & 26,830 & 0,467 & $2,527 \mathrm{E}-01$ \\
\hline OSBPL8 & 23,870 & 23,403 & 0,467 & $2,739 \mathrm{E}-01$ \\
\hline $\mathrm{BDH} 2$ & 24,268 & 23,800 & 0,467 & $5,762 \mathrm{E}-01$ \\
\hline HRAS & 24,505 & 24,033 & 0,472 & $3,194 \mathrm{E}-01$ \\
\hline SLC25A12 & 24,808 & 24,335 & 0,472 & $3,057 \mathrm{E}-01$ \\
\hline COPB1 & 26,385 & 25,913 & 0,473 & $5,484 \mathrm{E}-01$ \\
\hline ACLY & 23,675 & 23,200 & 0,475 & $6,793 \mathrm{E}-01$ \\
\hline SPTLC1 & 23,398 & 22,915 & 0,483 & $2,322 \mathrm{E}-01$ \\
\hline STAT1 & 25,950 & 25,458 & 0,493 & $4,316 \mathrm{E}-01$ \\
\hline PFKM & 21,854 & 21,351 & 0,503 & $6,654 \mathrm{E}-01$ \\
\hline MB & 20,354 & 19,840 & 0,514 & $3,349 \mathrm{E}-01$ \\
\hline ARSD & 23,008 & 22,490 & 0,518 & $3,750 \mathrm{E}-01$ \\
\hline FDXR & 23,438 & 22,918 & 0,520 & $2,431 \mathrm{E}-01$ \\
\hline ALG1 & 21,892 & 21,372 & 0,520 & $2,629 \mathrm{E}-01$ \\
\hline VDAC3 & 27,550 & 27,028 & 0,522 & $2,136 \mathrm{E}-01$ \\
\hline TECR & 29,193 & 28,663 & 0,530 & $2,827 \mathrm{E}-01$ \\
\hline ACSL3 & 27,410 & 26,875 & 0,535 & $3,013 \mathrm{E}-01$ \\
\hline ABCD3 & 23,928 & 23,390 & 0,537 & 2,199E-01 \\
\hline CALR & 31,548 & 31,000 & 0,547 & $2,532 \mathrm{E}-01$ \\
\hline $\mathrm{NR} 3 \mathrm{C} 1$ & 19,813 & 19,264 & 0,549 & $3,675 \mathrm{E}-01$ \\
\hline COPA & 26,315 & 25,758 & 0,557 & $4,800 \mathrm{E}-01$ \\
\hline CACNA2D1 & 29,680 & 29,113 & 0,567 & $2,016 \mathrm{E}-01$ \\
\hline CLTC & 29,645 & 29,073 & 0,572 & $3,323 \mathrm{E}-01$ \\
\hline CPT1A & 22,385 & 21,800 & 0,585 & $5,497 \mathrm{E}-01$ \\
\hline MAP2K3 & 20,678 & 20,092 & 0,586 & $3,940 \mathrm{E}-01$ \\
\hline PGM2 & 22,935 & 22,338 & 0,597 & $5,736 \mathrm{E}-01$ \\
\hline DPM1 & 26,360 & 25,755 & 0,605 & $1,979 \mathrm{E}-01$ \\
\hline SLC2A1 & 22,392 & 21,785 & 0,607 & $6,349 \mathrm{E}-01$ \\
\hline AP2S1 & 25,680 & 25,073 & 0,608 & $1,618 \mathrm{E}-01$ \\
\hline
\end{tabular}




\begin{tabular}{|c|c|c|c|c|}
\hline SLC1A5 & 25,230 & 24,620 & 0,610 & $1,312 \mathrm{E}-01$ \\
\hline CANX & 31,295 & 30,683 & 0,613 & $2,085 \mathrm{E}-01$ \\
\hline GNAI2 & 30,325 & 29,700 & 0,625 & $1,598 \mathrm{E}-01$ \\
\hline SACM1L & 28,115 & 27,488 & 0,627 & $1,812 \mathrm{E}-01$ \\
\hline FBP1 & 23,678 & 23,048 & 0,630 & $3,150 \mathrm{E}-01$ \\
\hline PIP4K2A & 23,038 & 22,403 & 0,635 & $1,606 \mathrm{E}-01$ \\
\hline ALG2 & 23,595 & 22,955 & 0,640 & $1,025 \mathrm{E}-01$ \\
\hline IDH2 & 29,333 & 28,690 & 0,643 & $1,983 \mathrm{E}-01$ \\
\hline ME2 & 25,603 & 24,935 & 0,667 & $3,972 \mathrm{E}-01$ \\
\hline SHMT2 & 24,360 & 23,690 & 0,670 & $3,134 \mathrm{E}-01$ \\
\hline LRP1 & 29,908 & 29,238 & 0,670 & $1,170 \mathrm{E}-01$ \\
\hline DPM3 & 24,243 & 23,570 & 0,672 & $1,376 \mathrm{E}-01$ \\
\hline GNA11 & 28,700 & 28,018 & 0,682 & $1,864 \mathrm{E}-01$ \\
\hline DOLPP1 & 22,315 & 21,623 & 0,693 & 2,389E-01 \\
\hline GNAS & 29,458 & 28,740 & 0,717 & $1,264 \mathrm{E}-01$ \\
\hline MICU1 & 20,311 & 19,590 & 0,721 & $2,059 \mathrm{E}-01$ \\
\hline TPM3 & 29,088 & 28,360 & 0,727 & $1,881 \mathrm{E}-01$ \\
\hline APOE & 28,933 & 28,190 & 0,743 & $2,369 \mathrm{E}-01$ \\
\hline MPDU1 & 25,863 & 25,118 & 0,745 & $9,698 \mathrm{E}-02$ \\
\hline CAMK2D & 24,433 & 23,688 & 0,745 & $5,675 \mathrm{E}-01$ \\
\hline PI4K2A & 22,875 & 22,128 & 0,747 & $1,302 \mathrm{E}-01$ \\
\hline STIM1 & 24,935 & 24,178 & 0,758 & $1,838 \mathrm{E}-01$ \\
\hline ATP2A2 & 28,628 & 27,868 & 0,760 & $1,590 \mathrm{E}-01$ \\
\hline GM2A & 22,595 & 21,833 & 0,762 & $1,586 \mathrm{E}-01$ \\
\hline SLC25A20 & 28,680 & 27,905 & 0,775 & $1,138 \mathrm{E}-01$ \\
\hline HACD2 & 27,880 & 27,098 & 0,783 & $2,516 \mathrm{E}-01$ \\
\hline CA2 & 25,323 & 24,518 & 0,805 & $2,055 \mathrm{E}-01$ \\
\hline NIPSNAP1 & 25,398 & 24,583 & 0,815 & $8,429 \mathrm{E}-02$ \\
\hline HACD3 & 26,843 & 26,020 & 0,822 & $6,652 \mathrm{E}-02$ \\
\hline LMAN2 & 28,353 & 27,530 & 0,823 & 4,972E-02 \\
\hline HEXB & 24,335 & 23,490 & 0,845 & $3,591 \mathrm{E}-01$ \\
\hline GOT2 & 26,125 & 25,280 & 0,845 & $5,826 \mathrm{E}-02$ \\
\hline SLC39A7 & 25,933 & 25,083 & 0,850 & $7,764 \mathrm{E}-02$ \\
\hline SLC25A13 & 25,613 & 24,755 & 0,857 & $9,936 \mathrm{E}-02$ \\
\hline PCK2 & 26,583 & 25,715 & 0,867 & $3,268 \mathrm{E}-01$ \\
\hline PRKACG & 25,093 & 24,224 & 0,869 & $6,189 \mathrm{E}-01$ \\
\hline GSR & 24,743 & 23,865 & 0,878 & $3,617 \mathrm{E}-01$ \\
\hline SLC27A3 & 23,958 & 23,063 & 0,895 & $1,105 \mathrm{E}-01$ \\
\hline HEXA & 23,358 & 22,430 & 0,928 & $4,077 \mathrm{E}-01$ \\
\hline GGT1 & 24,045 & 23,108 & 0,938 & $7,498 \mathrm{E}-02$ \\
\hline GDE1 & 23,328 & 22,349 & 0,978 & $2,612 \mathrm{E}-01$ \\
\hline TPM1 & 24,883 & 23,900 & 0,982 & $2,579 \mathrm{E}-01$ \\
\hline NAGK & 26,188 & 25,203 & 0,985 & $1,825 \mathrm{E}-01$ \\
\hline AGPAT1 & 21,845 & 20,845 & 1,000 & $2,648 \mathrm{E}-02$ \\
\hline PPT1 & 23,815 & 22,815 & 1,000 & $5,805 \mathrm{E}-02$ \\
\hline
\end{tabular}




\begin{tabular}{|c|c|c|c|c|}
\hline HBB & 33,225 & 32,223 & 1,003 & $1,557 \mathrm{E}-01$ \\
\hline ABCD2 & 24,280 & 23,260 & 1,020 & $1,571 \mathrm{E}-01$ \\
\hline AGPS & 25,013 & 23,978 & 1,035 & $5,669 \mathrm{E}-02$ \\
\hline PITPNB & 26,260 & 25,225 & 1,035 & 1,039E-01 \\
\hline SEC24C & 22,814 & 21,740 & 1,074 & $3,334 \mathrm{E}-01$ \\
\hline RPTOR & 22,558 & 21,454 & 1,104 & $3,708 \mathrm{E}-01$ \\
\hline GNA13 & 27,445 & 26,340 & 1,105 & $1,835 \mathrm{E}-02$ \\
\hline GNAQ & 27,898 & 26,770 & 1,128 & 4,301E-02 \\
\hline SLC3A2 & 28,243 & 27,103 & 1,140 & $4,426 \mathrm{E}-02$ \\
\hline ADPGK & 25,058 & 23,908 & 1,150 & $2,151 \mathrm{E}-02$ \\
\hline HBB & 23,085 & 21,925 & 1,160 & $2,465 \mathrm{E}-01$ \\
\hline LMF2 & 24,653 & 23,488 & 1,165 & $1,924 \mathrm{E}-01$ \\
\hline ATP1A2 & 21,043 & 19,860 & 1,183 & $2,667 \mathrm{E}-01$ \\
\hline LPCAT3 & 25,613 & 24,420 & 1,193 & $1,589 \mathrm{E}-02$ \\
\hline FAF2 & 26,448 & 25,210 & 1,238 & $4,833 \mathrm{E}-02$ \\
\hline LPL & 26,953 & 25,710 & 1,243 & $6,047 \mathrm{E}-02$ \\
\hline FLOT1 & 29,355 & 28,093 & 1,263 & $9,666 \mathrm{E}-03$ \\
\hline SGPL1 & 24,848 & 23,585 & 1,263 & $2,568 \mathrm{E}-02$ \\
\hline MARCKS & 25,815 & 24,530 & 1,285 & $3,148 \mathrm{E}-02$ \\
\hline GYG1 & 23,600 & 22,303 & 1,297 & $2,577 \mathrm{E}-01$ \\
\hline ALG9 & 21,539 & 20,230 & 1,308 & $2,007 \mathrm{E}-01$ \\
\hline TPM4 & 27,108 & 25,795 & 1,313 & $4,736 \mathrm{E}-02$ \\
\hline FTO & 20,151 & 18,818 & 1,333 & $8,460 \mathrm{E}-02$ \\
\hline CETP & 22,283 & 20,895 & 1,388 & 2,944E-01 \\
\hline LBR & 23,783 & 22,233 & 1,550 & $3,959 \mathrm{E}-03$ \\
\hline FHL2 & 21,466 & 19,898 & 1,568 & 6,794E-02 \\
\hline FLOT2 & 28,985 & 27,415 & 1,570 & $1,921 \mathrm{E}-03$ \\
\hline GPAM & 29,103 & 27,513 & 1,590 & $1,747 \mathrm{E}-02$ \\
\hline FTH1 & 30,675 & 29,048 & 1,627 & $2,952 \mathrm{E}-02$ \\
\hline CERS2 & 23,558 & 21,928 & 1,630 & $4,586 \mathrm{E}-03$ \\
\hline EBP & 26,673 & 25,015 & 1,658 & $3,995 \mathrm{E}-03$ \\
\hline GPD2 & 27,785 & 26,045 & 1,740 & $4,302 \mathrm{E}-03$ \\
\hline FAAH & 22,813 & 21,063 & 1,750 & $1,843 \mathrm{E}-02$ \\
\hline TSTA3 & 22,605 & 20,803 & 1,802 & 4,971E-02 \\
\hline STS & 24,490 & 22,675 & 1,815 & 6,994E-02 \\
\hline MBOAT7 & 21,657 & 19,817 & 1,839 & 6,207E-02 \\
\hline RENBP & 21,822 & 19,949 & 1,873 & $5,151 \mathrm{E}-02$ \\
\hline CISD2 & 26,440 & 24,495 & 1,945 & $2,256 \mathrm{E}-03$ \\
\hline APOB & 32,963 & 31,000 & 1,962 & $5,385 \mathrm{E}-02$ \\
\hline APOA2 & 28,030 & 26,020 & 2,010 & $7,845 \mathrm{E}-03$ \\
\hline PLD3 & 25,263 & 23,193 & 2,070 & $2,483 \mathrm{E}-03$ \\
\hline BAX & 22,540 & 20,457 & 2,083 & $1,378 \mathrm{E}-02$ \\
\hline GSN & 30,615 & 28,500 & 2,115 & $1,344 \mathrm{E}-03$ \\
\hline ATP1A1 & 25,875 & 23,717 & 2,158 & $2,182 \mathrm{E}-01$ \\
\hline LSS & 30,078 & 27,870 & 2,208 & $4,347 \mathrm{E}-04$ \\
\hline
\end{tabular}




\begin{tabular}{|c|c|c|c|c|}
\hline PON1 & 26,048 & 23,833 & 2,215 & $1,494 \mathrm{E}-02$ \\
\hline HSD17B11 & 26,740 & 24,433 & 2,308 & $3,006 \mathrm{E}-03$ \\
\hline APOC2 & 22,375 & 20,002 & 2,373 & $8,739 \mathrm{E}-02$ \\
\hline APOC3 & 26,745 & 24,325 & 2,420 & $4,428 \mathrm{E}-02$ \\
\hline ALB & 33,525 & 31,055 & 2,470 & $9,886 \mathrm{E}-04$ \\
\hline AGT & 22,485 & 20,000 & 2,485 & $6,158 \mathrm{E}-03$ \\
\hline SLC44A2 & 25,845 & 23,323 & 2,523 & $1,477 \mathrm{E}-03$ \\
\hline ALDH3B1 & 24,705 & 22,160 & 2,545 & $3,735 \mathrm{E}-03$ \\
\hline CALML5 & 22,247 & 19,691 & 2,556 & $3,496 \mathrm{E}-02$ \\
\hline ALDH1A3 & 22,230 & 19,656 & 2,573 & 2,433E-02 \\
\hline LIPA & 23,090 & 20,432 & 2,658 & $2,828 \mathrm{E}-03$ \\
\hline MYL3 & 23,539 & 20,846 & 2,693 & $1,238 \mathrm{E}-01$ \\
\hline STAT2 & 24,208 & 21,466 & 2,741 & $1,416 \mathrm{E}-02$ \\
\hline ITPR1 & 24,040 & 21,073 & 2,967 & $1,057 \mathrm{E}-03$ \\
\hline CYP1B1 & 22,454 & 19,444 & 3,010 & $1,825 \mathrm{E}-02$ \\
\hline SERPINA5 & 21,955 & 18,943 & 3,012 & 2,390E-04 \\
\hline PLTP & 23,656 & 20,610 & 3,046 & $9,504 \mathrm{E}-02$ \\
\hline ARG1 & 24,455 & 21,233 & 3,223 & $4,346 \mathrm{E}-02$ \\
\hline UBB & 29,808 & 26,523 & 3,285 & $5,891 \mathrm{E}-03$ \\
\hline A2M & 29,603 & 26,253 & 3,350 & $1,408 \mathrm{E}-03$ \\
\hline APOC4 & 25,763 & 22,380 & 3,383 & $6,086 \mathrm{E}-02$ \\
\hline APOM & 26,345 & 22,918 & 3,428 & $5,010 \mathrm{E}-03$ \\
\hline ALOX5AP & 24,353 & 20,849 & 3,503 & $2,028 \mathrm{E}-03$ \\
\hline VTN & 30,165 & 26,660 & 3,505 & 1,790E-03 \\
\hline PLG & 25,163 & 21,618 & 3,544 & $2,126 \mathrm{E}-02$ \\
\hline PTGS1 & 24,185 & 20,482 & 3,703 & $2,335 \mathrm{E}-04$ \\
\hline RAC2 & 23,092 & 19,358 & 3,733 & $3,912 \mathrm{E}-03$ \\
\hline ALOX5 & 22,758 & 18,994 & 3,764 & 7,134E-04 \\
\hline HSD17B7 & 23,150 & 19,384 & 3,766 & $2,950 \mathrm{E}-05$ \\
\hline GMDS & 22,397 & 18,631 & 3,766 & 2,509E-03 \\
\hline CTNNB1 & 23,310 & 19,526 & 3,784 & $5,420 \mathrm{E}-03$ \\
\hline LEPR & 26,410 & 22,589 & 3,821 & $4,565 \mathrm{E}-04$ \\
\hline TBXAS1 & 23,670 & 19,704 & 3,966 & 2,679E-04 \\
\hline CIDEA & 22,695 & 18,691 & 4,004 & 8,299E-04 \\
\hline AHSG & 25,720 & 21,503 & 4,217 & $2,558 \mathrm{E}-03$ \\
\hline FCER1G & 24,295 & 20,024 & 4,271 & $1,277 \mathrm{E}-03$ \\
\hline TTR & 26,263 & 21,823 & 4,439 & $1,271 \mathrm{E}-04$ \\
\hline TGM2 & 25,733 & 21,193 & 4,540 & $2,875 \mathrm{E}-04$ \\
\hline APOC1 & 26,755 & 22,194 & 4,561 & $6,490 \mathrm{E}-03$ \\
\hline NCEH1 & 25,235 & 20,393 & 4,842 & $1,341 \mathrm{E}-04$ \\
\hline $\mathrm{APOH}$ & 28,385 & 23,403 & 4,983 & $2,548 \mathrm{E}-05$ \\
\hline GGT5 & 28,585 & 22,675 & 5,910 & $3,971 \mathrm{E}-05$ \\
\hline RAF1 & 26,733 & 20,811 & 5,922 & 4,107E-05 \\
\hline $\mathrm{CP}$ & 28,283 & 21,710 & 6,573 & $4,466 \mathrm{E}-05$ \\
\hline
\end{tabular}


Fig 1

A

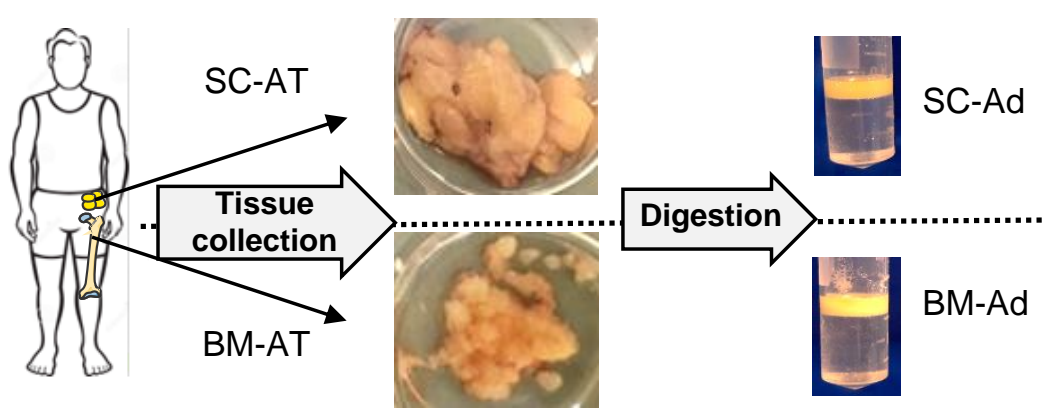

B

BM-AT

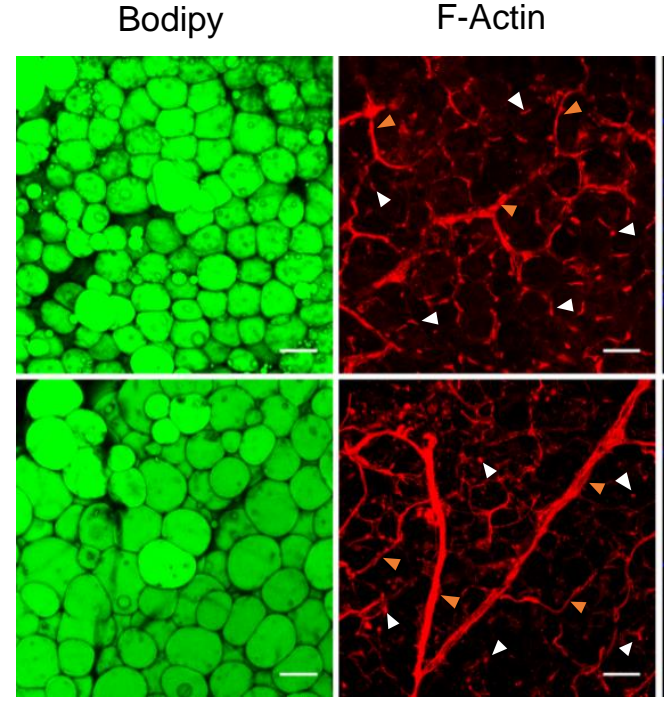

C
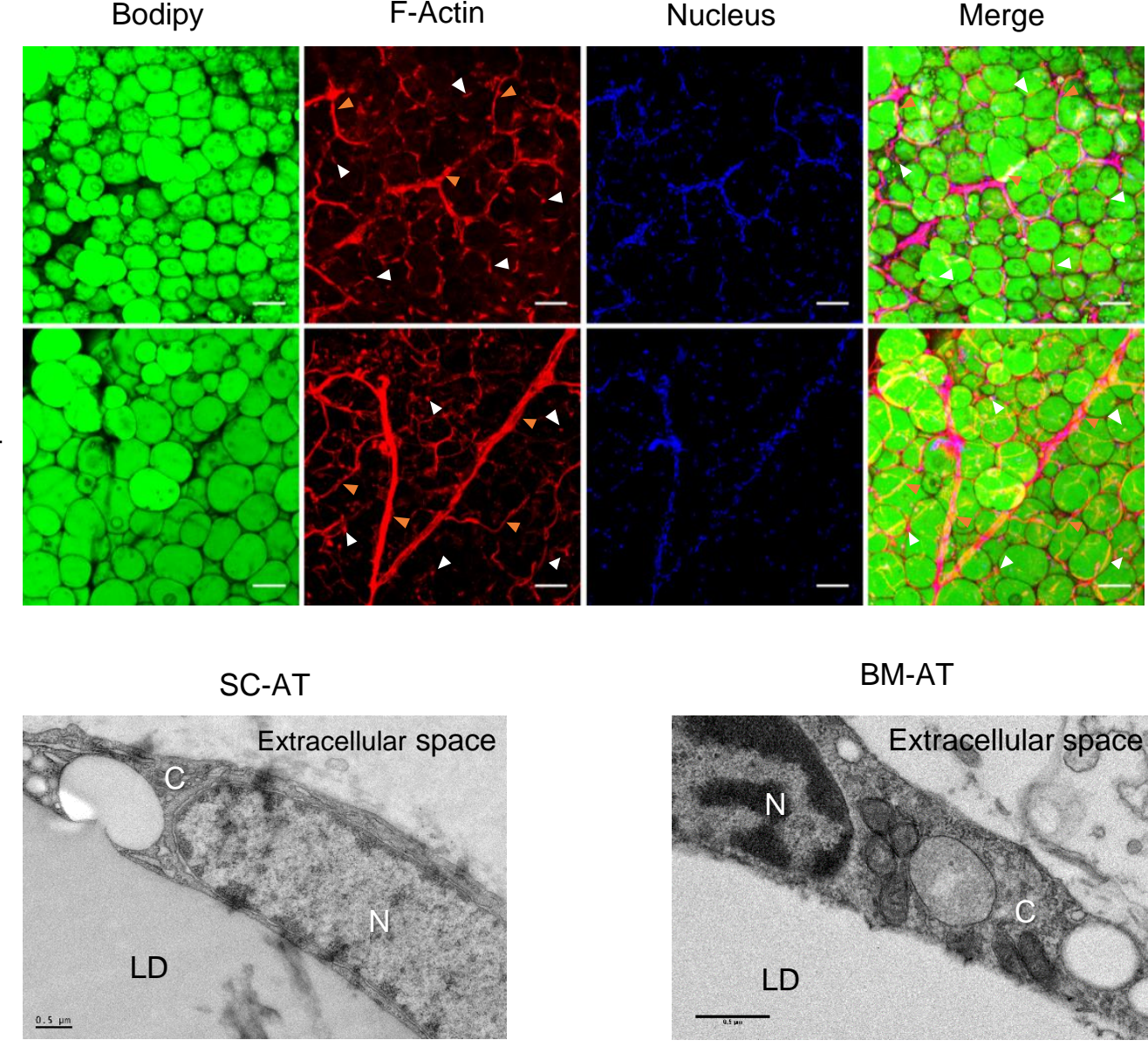

D

Bodipy

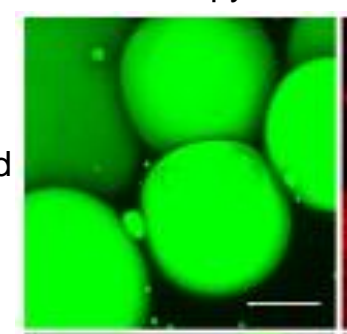

SC-Ad

BM-Ad

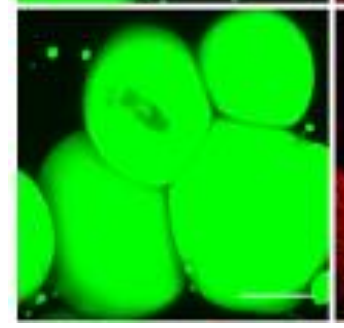

F-Actin
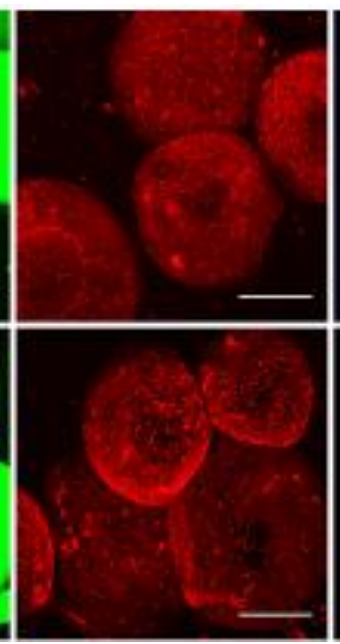

BM-AT



Nucleus

Merge
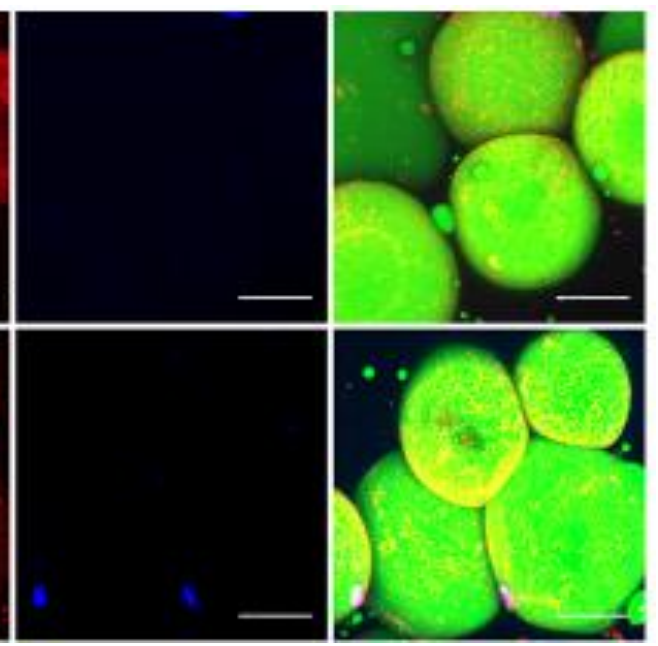


\section{Fig EV1}

A

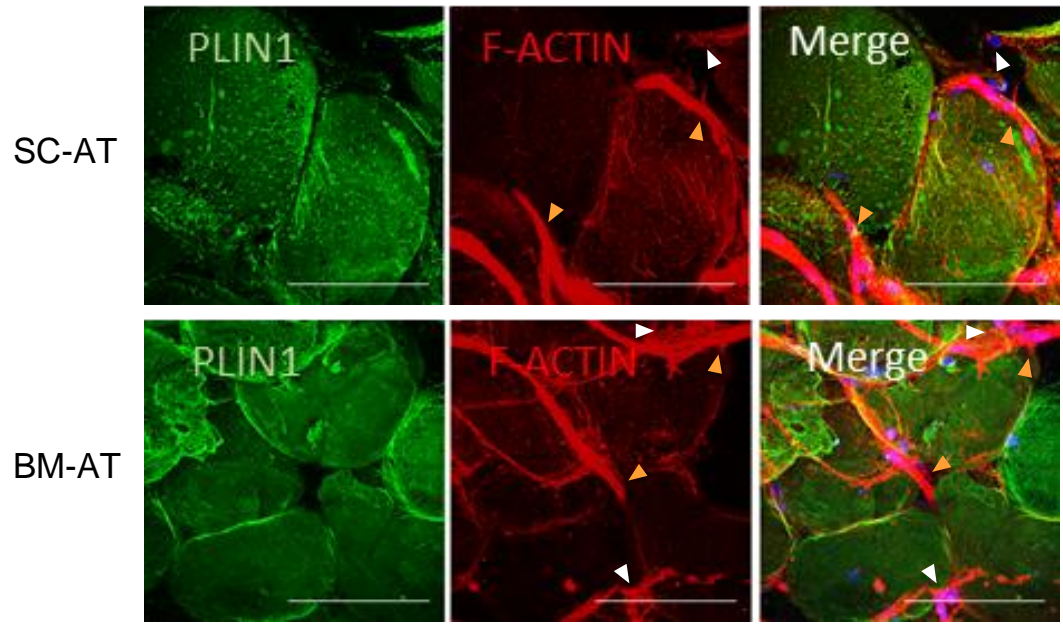

B

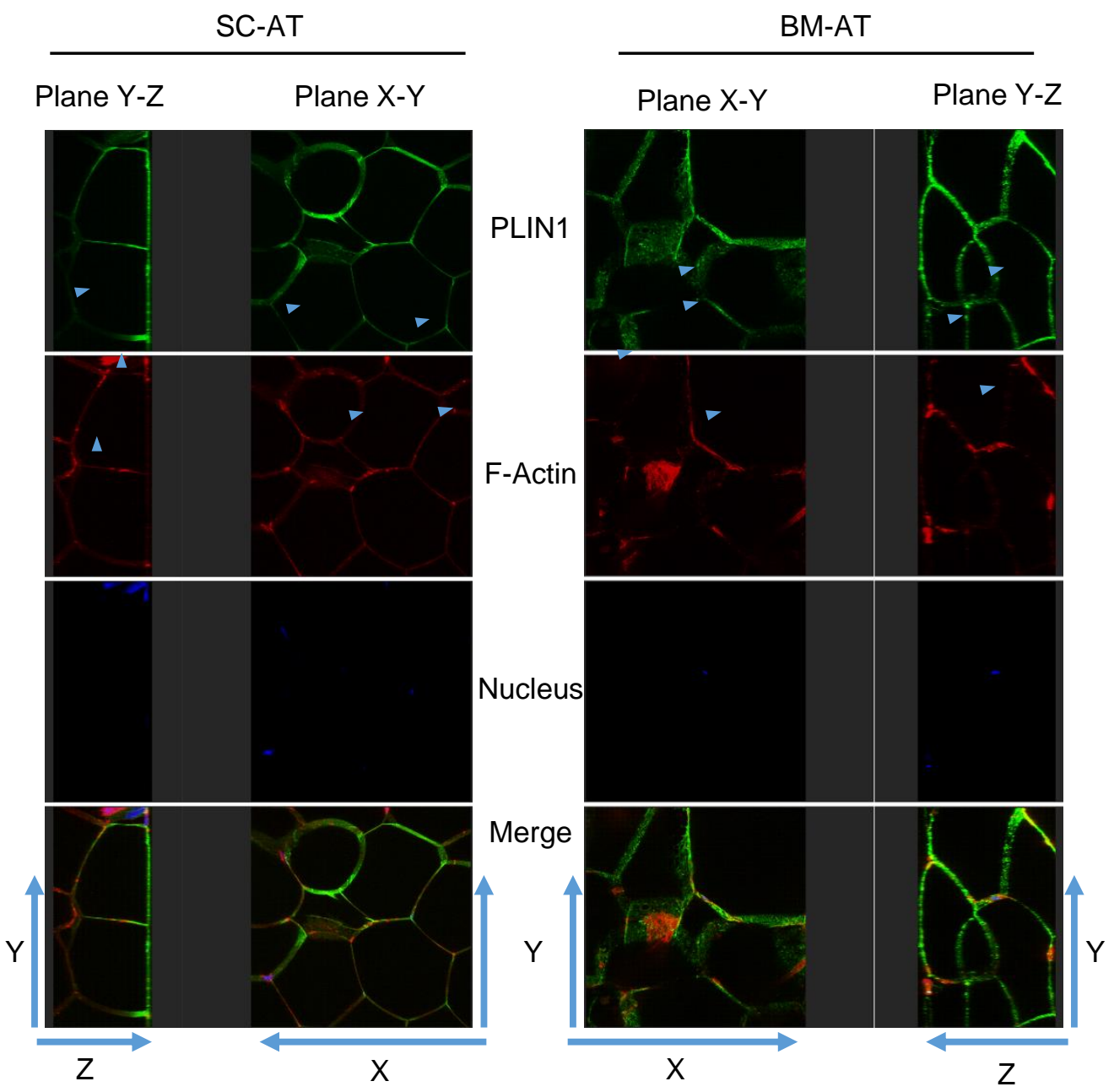


A

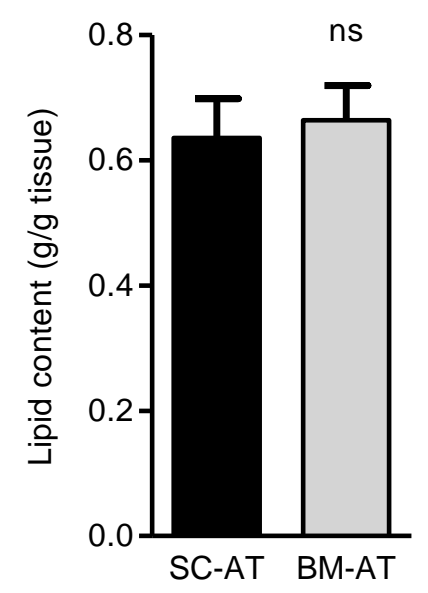

C

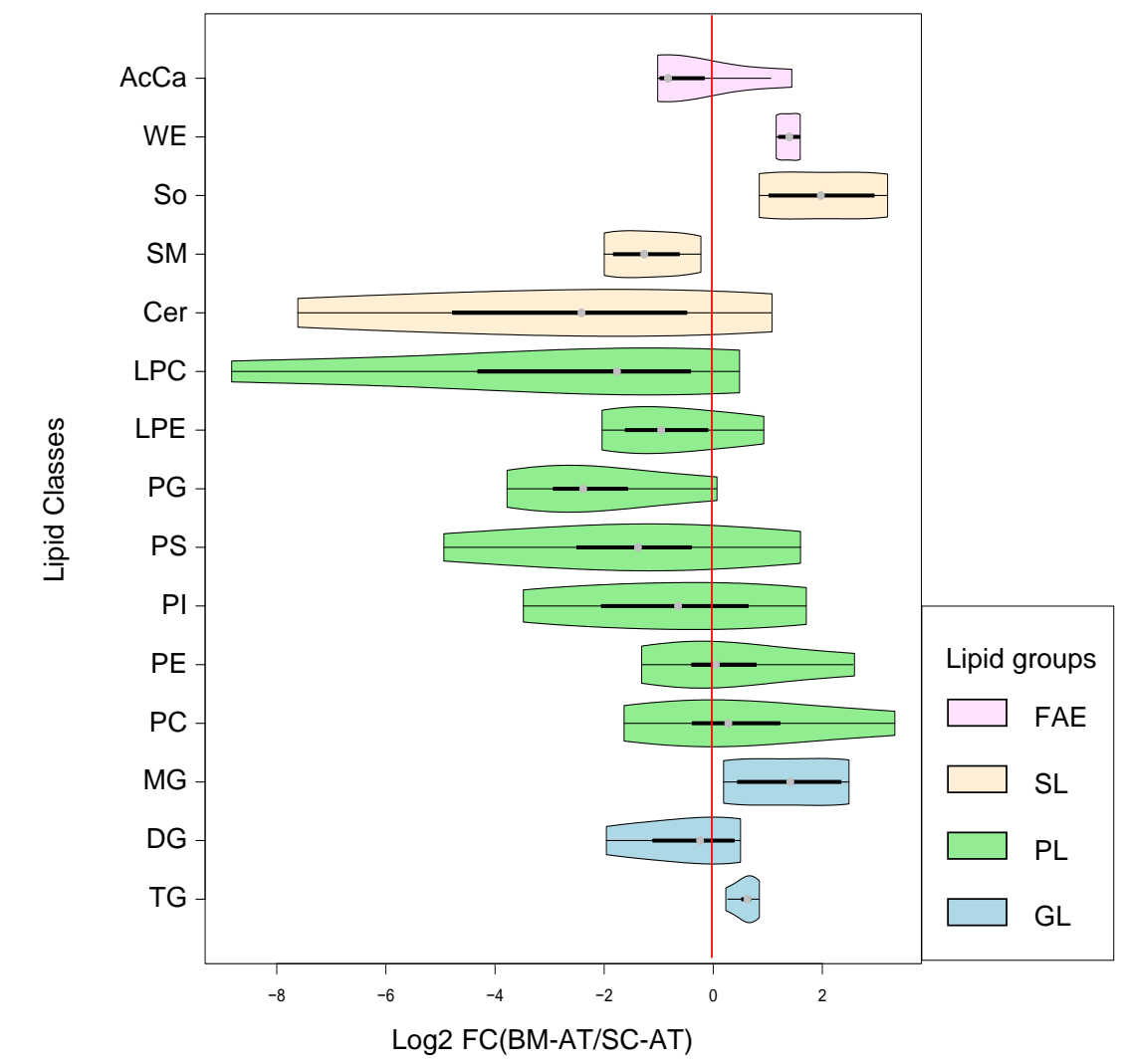

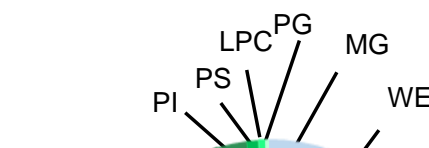

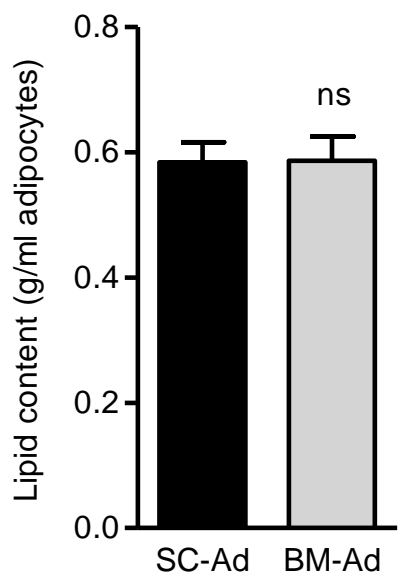

B

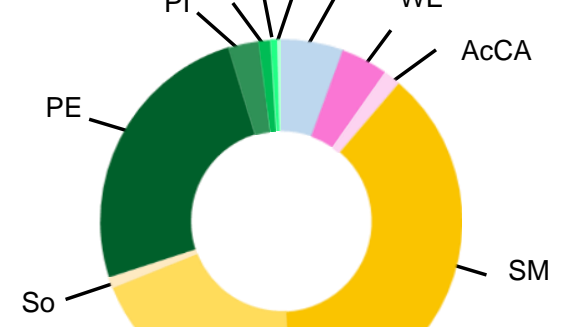

D

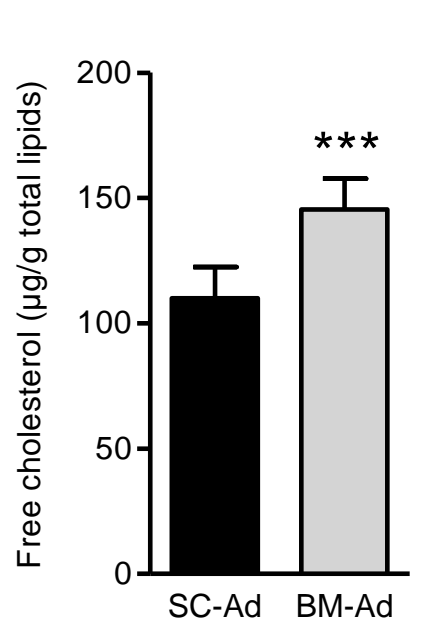

D
Lipid groups

FAE

SL

PL

GL 


\section{Fig EV2}

A

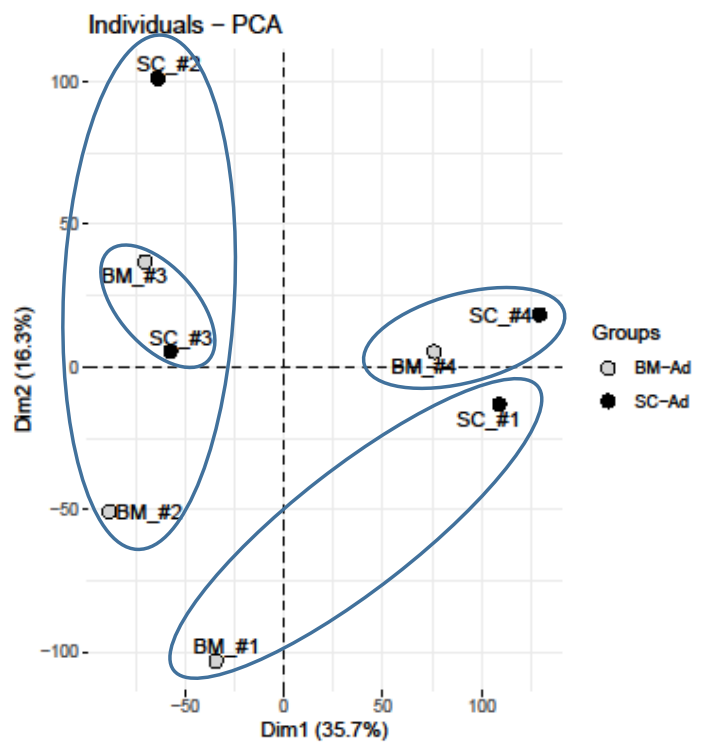

B
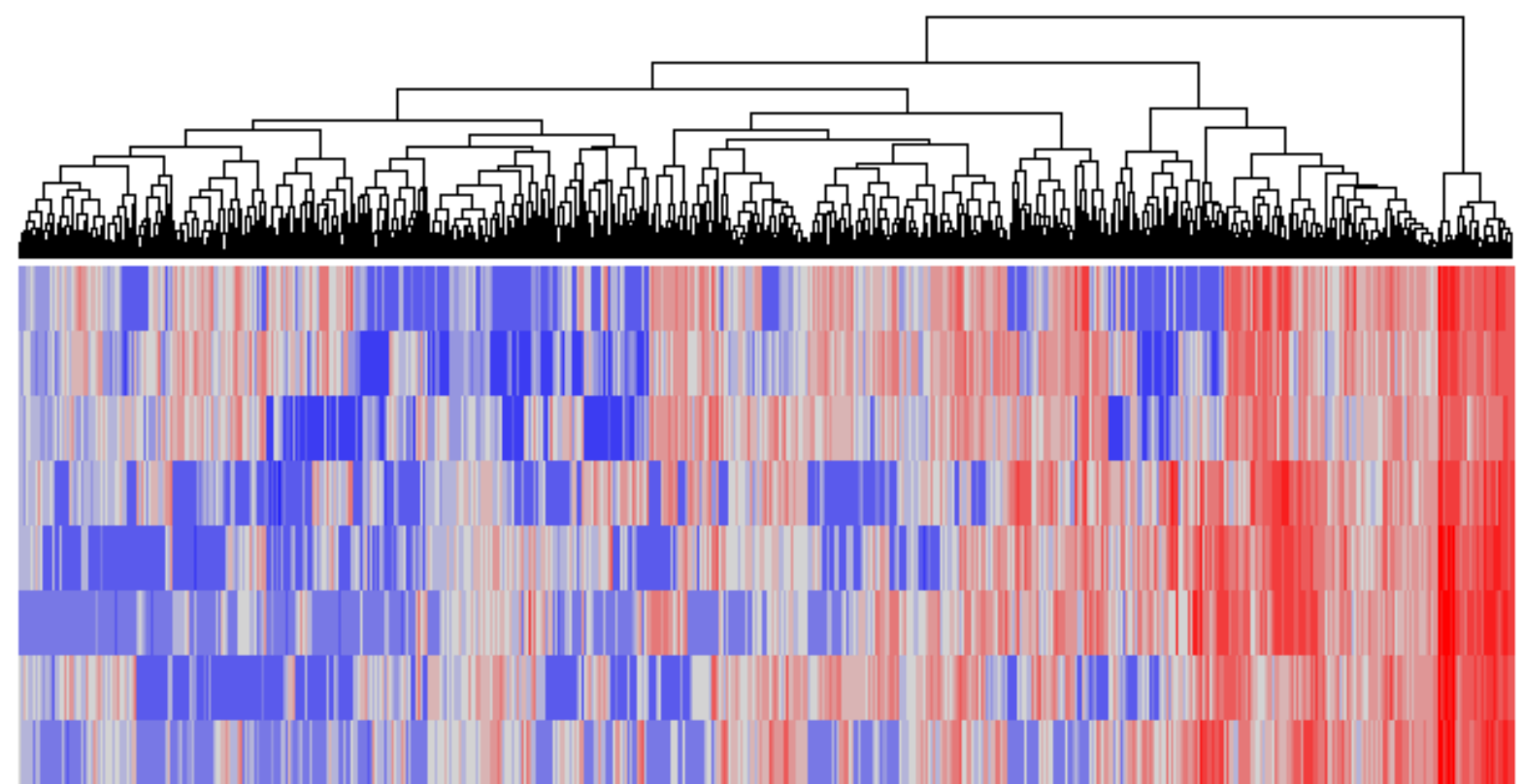

SC_\#1

SC_\#4

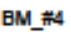

SC_\#2

BM_E3

$\mathrm{SC}+3$

日M_"\#1

BM_\#2

C

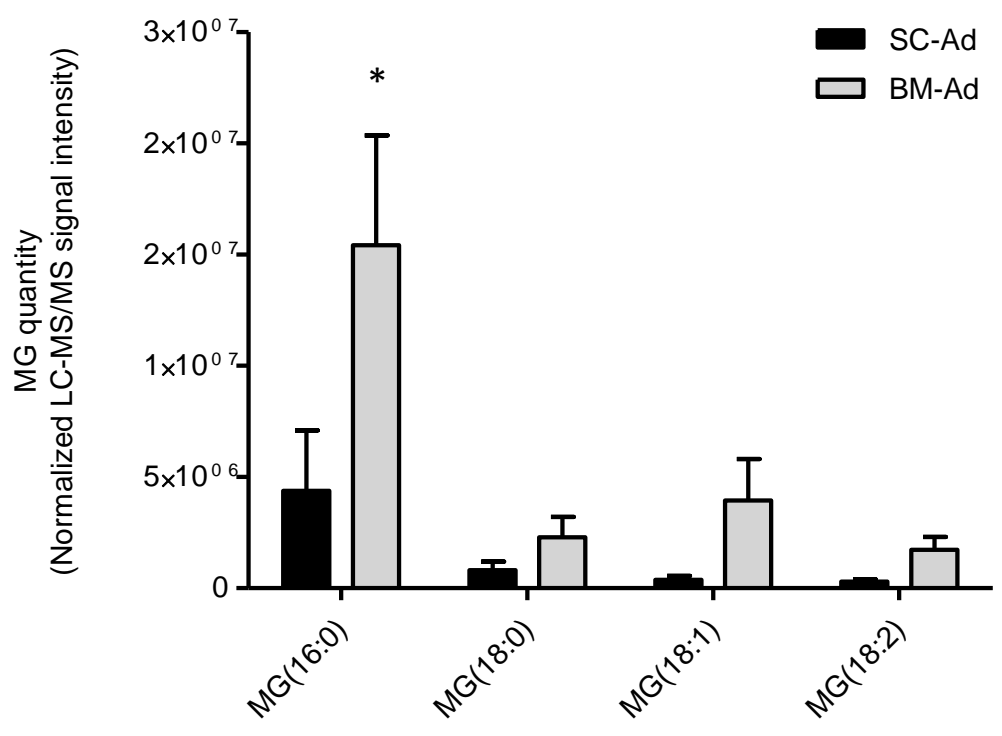


A



C

Response to Elevated Platelet Cytosolic Ca2+


B

- Unchanged

- Enriched in BM-Ad

- Down regulated in BM-Ad

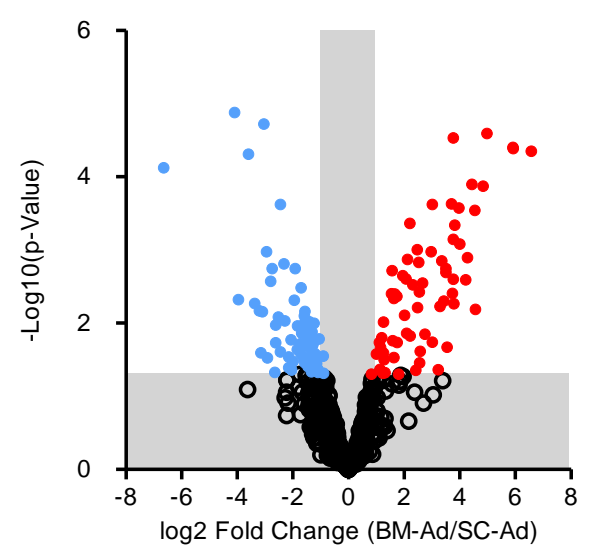

D

Lipoprotein Metabolism
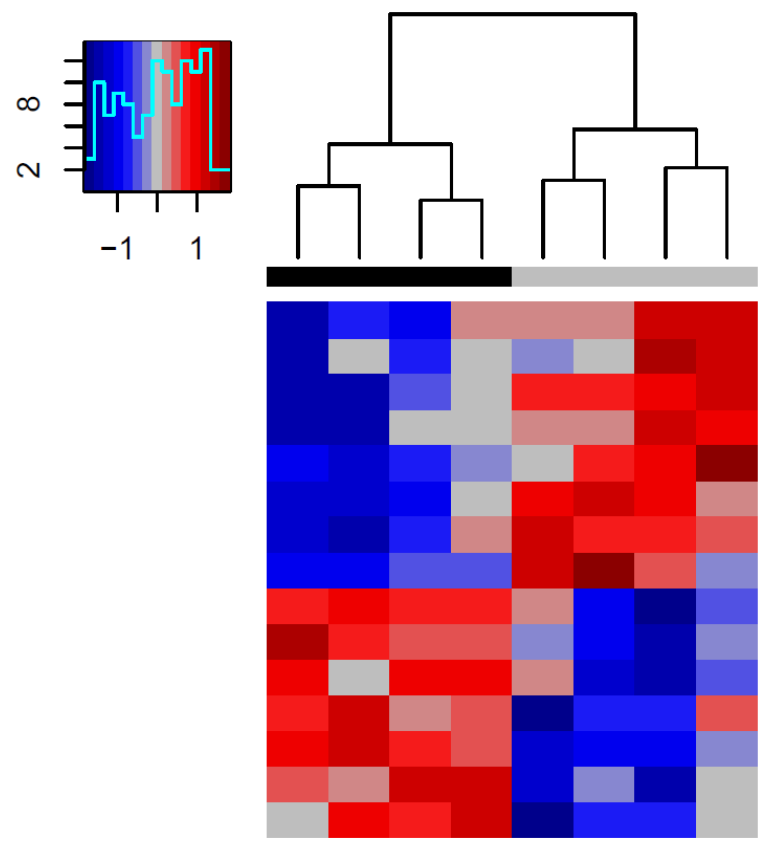

APOA2

APOC3

ALB

APOC1

CIDEA

NCEH1

A2M

LIPA

SAR1B

LIPE

FABP4

VLDLR

MGLL

SH3KBP 1

PLIN1 


\section{Fig EV3}

A

Data Quality Control

Selection of proteins

detected at least in 3 patients
Data filtering

Identification of protein involved in lipid and glucose metabolism
Statistical Analyses

Multivariate analysis

Linear statistical Model Analysis
LC MS/MS 3787 proteins identified
3259 proteins Identified
612 proteins selected
68 proteins upregulated in BM-Ad 67 proteins downregulated in BM-Ad

\section{Data preprocessing}

B

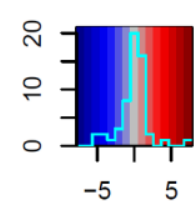

Adipokines expression
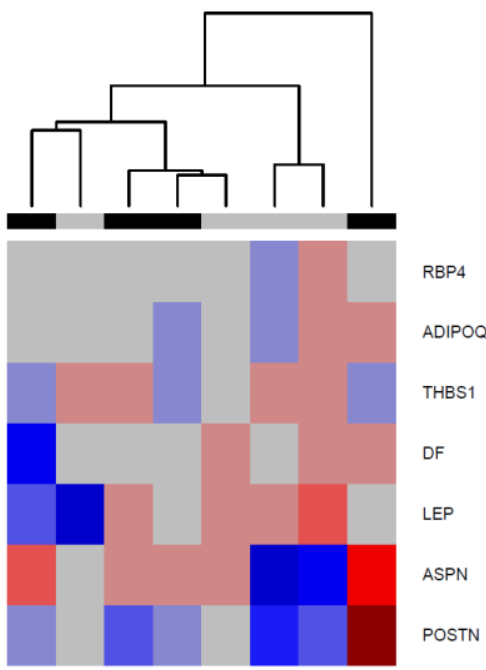

MHIIII

Arachidonic Acid Metabolism

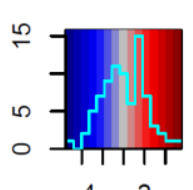

$-42$
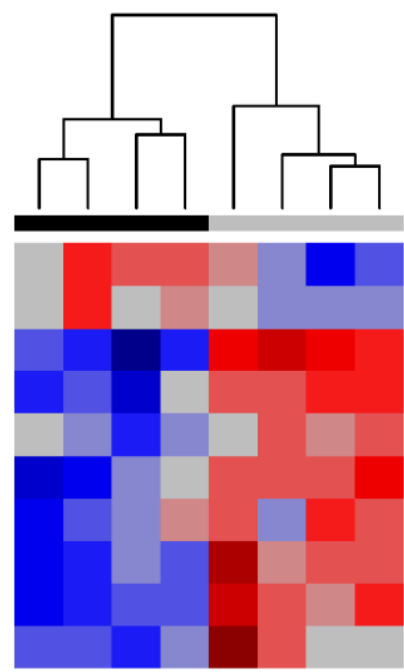

PTGR2

AKR1C3

GGT5

PTGS1

FAAH

ALOX5AP

PON1

ALOX5

TBXAS1

CYP1B1
C

\section{Data analysis}

Bioinformatic Analyses

Pathway enrichment

Kmeans clustering
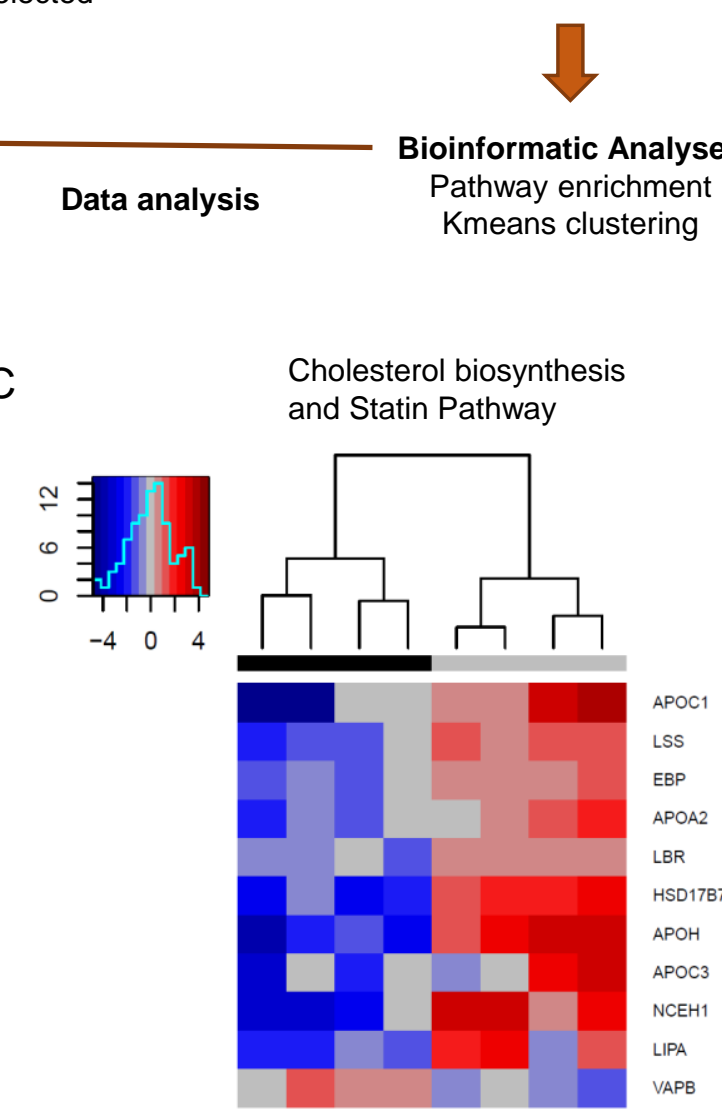

APOC1

LSS

EBP

APOA2

LBR

HSD17B7

$\mathrm{APOH}$

APOC3

NCEH1

LIPA

VAPB

111111

E

Fatty Acid Metabolism
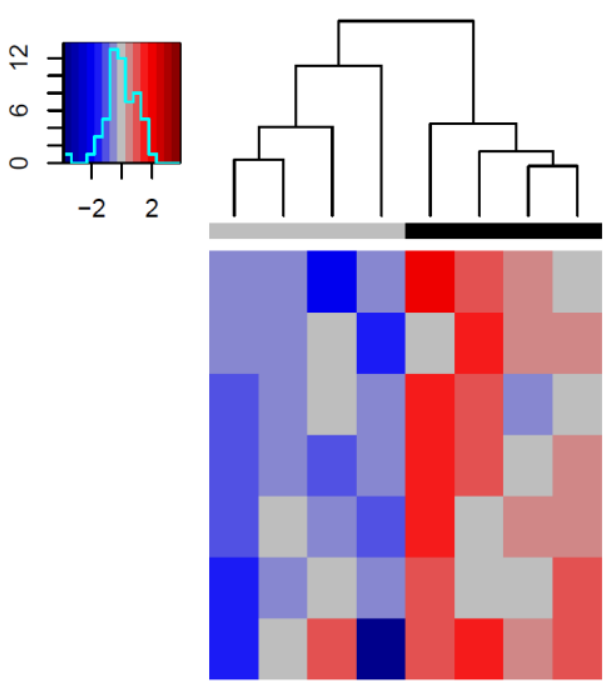

ACADSB

ADH5

ECHS1

ACAT1

ELOVL5

HADH

$\mathrm{ADH} 1 \mathrm{C}$ 
Fig 4

A

$$
\frac{\# 1}{S C M} \quad \frac{\# 2}{S C ~ M} \quad \frac{\# 3}{S C ~ M}
$$

$\mathrm{HSL} \sim-\infty-$

ATGL $m=5$

MAGL $=-$

$\beta$ - actin

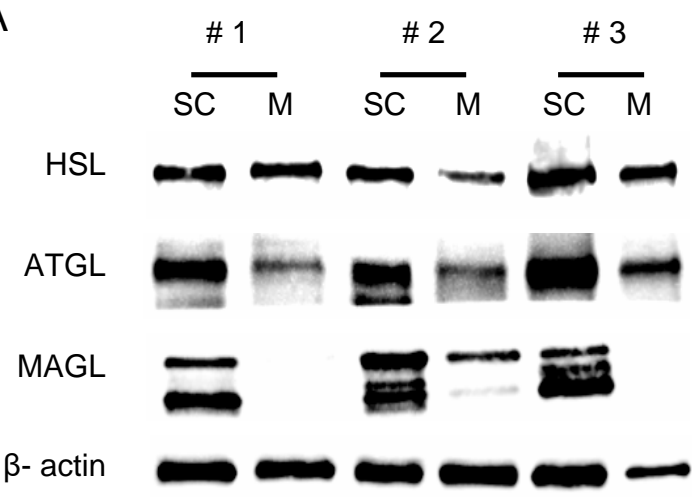

B

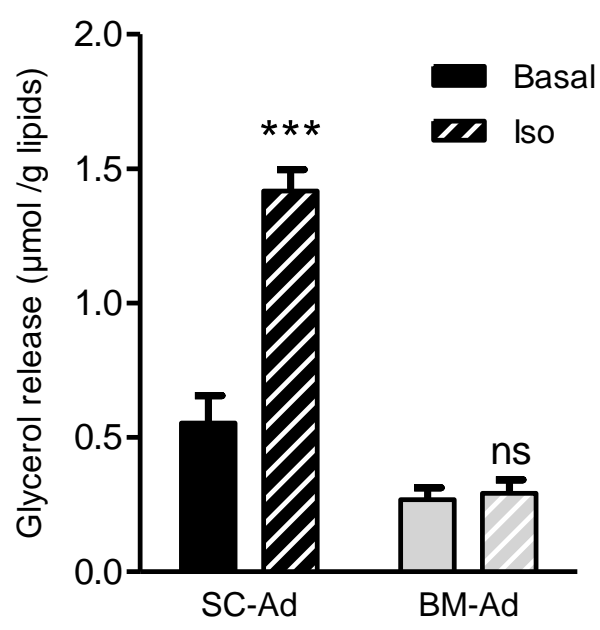

D

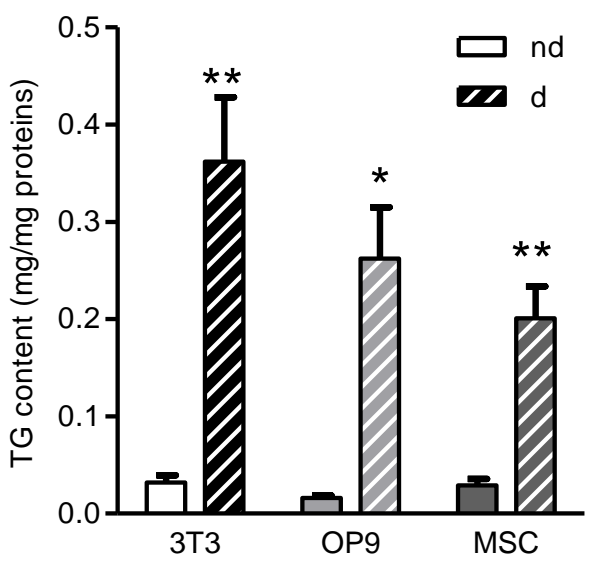

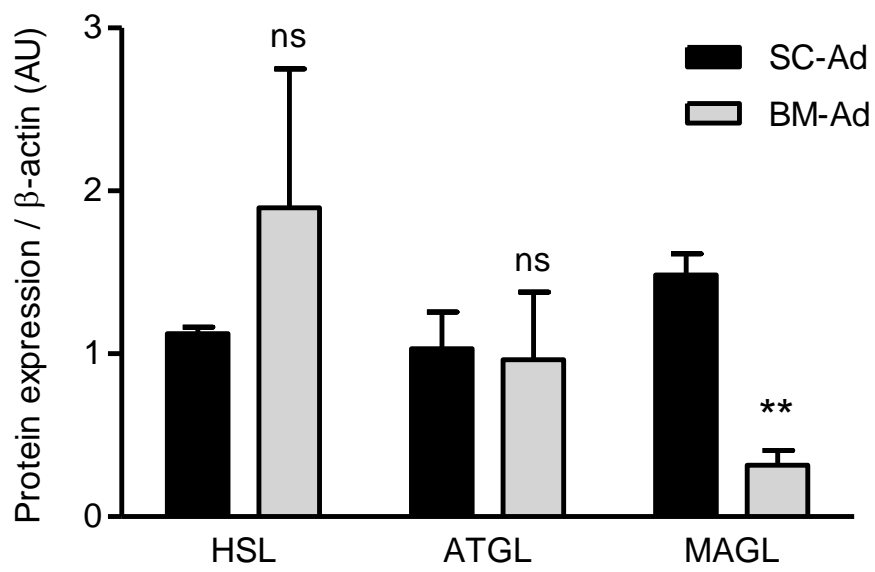

C

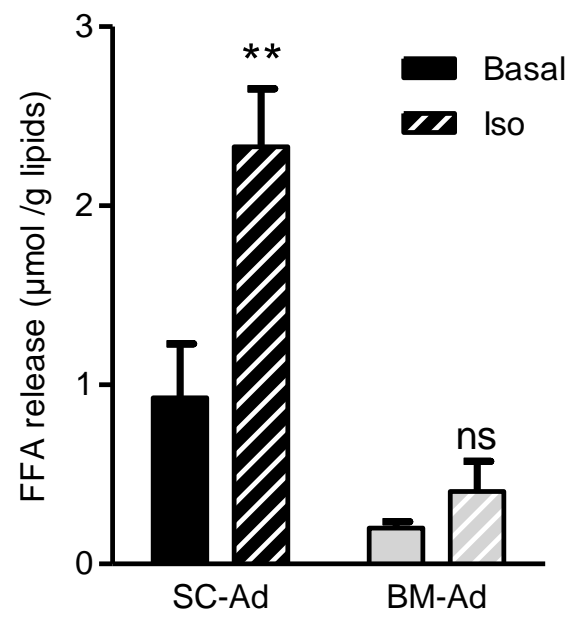

E

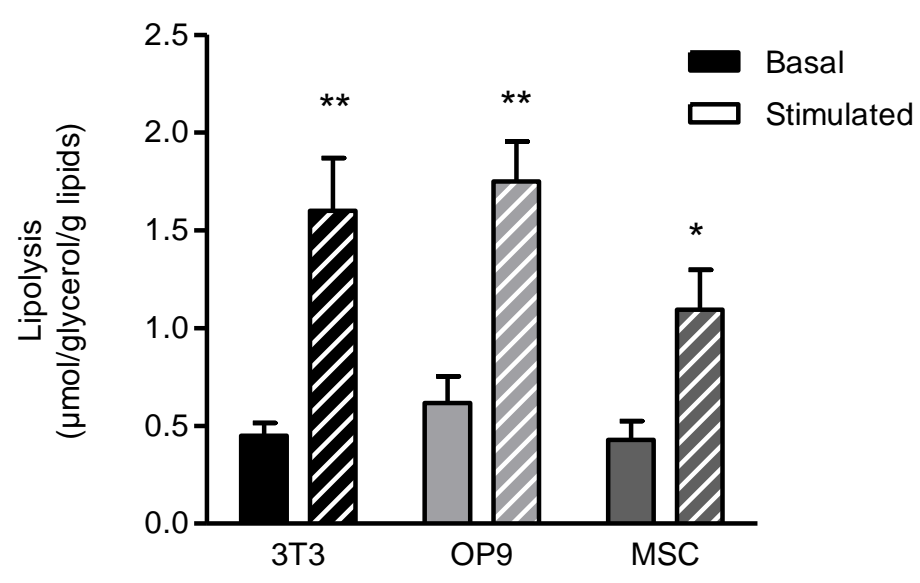

